\title{
A System Dynamics View of the Acute Bed Blockage Problem in the Irish Healthcare System
}

Waleed Abo Hamad

Technological University Dublin, waleed.abohamad@tudublin.ie

Wael Rashwan

Technological University Dublin, wael.rashwan@tudublin.ie

Amr Arisha

Technological University Dublin, amr.arisha@tudublin.ie

Follow this and additional works at: https://arrow.tudublin.ie/buschmanart

Part of the Business Administration, Management, and Operations Commons

\section{Recommended Citation}

Abo-Hamad, W., Rashwan, W., \& Arisha, A. (2015). A system dynamics view of the acute bed blockage problem in the Irish healthcare system. European Journal of Operational Research, 247(1), 276-293.

doi:10.1016/j.ejor.2015.05.043

This Article is brought to you for free and open access by the School of Management at ARROW@TU Dublin. It has been accepted for inclusion in Articles by an authorized administrator of ARROW@TU Dublin. For more information, please contact arrow.admin@tudublin.ie, aisling.coyne@tudublin.ie,gerard.connolly@tudublin.ie.

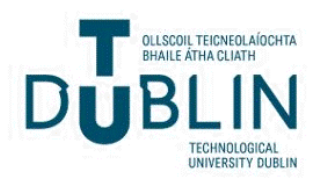




\title{
A System Dynamics View of the Acute Bed Blockage Problem in the Irish Healthcare System
}

\author{
Wael Rashwan \\ Email: wael.rashwan@mydit.ie, Mobile:+353831577482 \\ Waleed Abo-Hamad \\ Email: waleed.abohamad@dit.ie, Mobile: +353831577482 \\ Amr Arisha \\ Email: amr.arisha@dit.ie, Mobile: +353831577482 \\ 3S Group, College of Business \\ Dublin Institute of Technology \\ Dublin 2, Ireland
}

\begin{abstract}
Global population ageing is creating immense pressures on hospitals and other healthcare services, compromising their abilities to meet the growing demand from elderly patients. Current demand-supply gaps result in prolonged waiting times in emergency departments (EDs), and several studies have focused on improving ED performance. However, the overcrowding in EDs generally stems from delayed patient flows to inpatient wards - which are congested with inpatients waiting for beds in postacute facilities. This problem of bed blocking in acute hospitals causes substantial cost burdens on hospitals. This study presents a system dynamics methodology to model the dynamic flow of elderly patients in the Irish healthcare system aimed at gaining a better understanding of the dynamic complexity caused by the system's various parameters. The model evaluates the stock and flow interventions that Irish healthcare executives have proposed to address the problem of delayed discharges, and ultimately reduce costs. The anticipated growth in the nation's demography is also incorporated in the model. Policy makers can also use the model to identify the potential strategic risks that might arise from the unintended consequences of new policies designed to overcome the problem of the delayed discharge of elderly patients.
\end{abstract}

Keywords: Delayed discharge; System Dynamics; Simulation; Patient pathways; Capacity planning; Irish Healthcare System 


\section{INTRODUCTION}

The fact that there are more elderly people than ever before is an indicator of advances in global health (McDermid \& Bagshaw 2011). Worldwide, there are around 600 million elderly people commonly defined as those aged 65 years and over (Paul \& Hariharan 2007) - a total that is set to double by 2025 , and to reach virtually two billion by 2050 (WHO 2011). There are currently 108 million elderly people in Europe: they constitute $15 \%$ of the continent's population, a proportion that is expected to reach $26 \%$ by 2050 (Piersa et al. 2013). In Ireland, the elderly population is projected to grow from 0.5 to 1.3 million over the next 30 years (Connell \& Pringle 2004). As people across the globe age - causing the cost of providing health and social care to rise - finding innovative approaches to delivering such services is becoming increasingly important. Discrete-Event Simulation (DES) has been proven to be an excellent and flexible tool for modelling processes in such complex stochastic environments (Eldabi et al. 2006; Duguay \& Chetouane 2007). Healthcare managers apply DES to assess current performance, to predict the impact of operational changes, and to examine the trade-offs between system variables (Litvak et al. 2008; Thorwarth et al. 2009; Abo-Hamad \& Arisha 2013; Abo-Hamad \& Arisha 2014). DES seeks to reduce a system down to its basic elements in order to study them in detail and understand the types of interactions that exist between them ( $\mathrm{Ng}$ et al. 2011).

This paper describes a nation-wide project carried out for the Irish Health Service Executive (HSE), considering all the country's public acute hospitals using data from 2010 as the base year. The project's goal is to find solutions to help overcome the problem of the delayed discharge of elderly patients, and plan to meet growing demand over the next five years. The project's first phase began in 2012 when a DES model was developed to model the flow of elderly patients through Irish hospitals (Ragab et al. 2013). The main focus of this model is investigate the impact of transitional beds to mitigate the delayed discharge problem in short term (i.e., one year). Although the DES method was found to be a very powerful tool for understanding such systems, several problems arose in this phase whose sources were difficult to identify. Data problems included issues of irrelevance, insufficiency and inaccuracy. Attempting to overcome these challenges, the study recommended using a System Dynamics (SD) methodology, which offers a wider system view than DES. SD is more useful for modelling large and 
complex systems that takes the holistic view (Brailsford \& Hilton 2001), as well as for modelling dynamic changes over time explicitly.

Healthcare systems often have many different stakeholders- e.g., health providers, medical/professional interests, funders, and patients' groups - and actions and activities undertaken in one part of the healthcare system designed to meet the needs of one set of stakeholders can often result in unexpected and unwanted consequences elsewhere, which can work against the interests of another set. SD offers a methodology that can help businesses and government institutions to develop strategy and analyse policy interventions by modelling causal relationships and feedback systems (Sweetser 1999). The method has been applied to model such strategic aspects of policy and national issues in care systems as patient's pathways (Monefeldt et al. 2000) and planning care for the elderly (Wolstenholme 1999; Walker \& Haslett 2001; Desai et al. 2008) .

The primary objective of this study is to deliver a holistic and strategic national level capacityplanning model which can support policy makers in making decisions that are well assessed and carry fewer risks for elderly patients. It is also envisaged that this effort will have a positive impact on the delayed discharge issue.

The remainder of the paper is organized as follows. Section 2 presents a background and defines the challenges and problems facing the Irish healthcare system. Section 3 reviews the literature, focusing on studies that have used SD methodology to model patient pathways so as to address the problem of delayed patient discharges. Section 4 presents the case study of delayed discharges in the Irish healthcare system, which led to the development of the SD model. This section describes the model development and conceptualization, and presents our data calibration and model validation approaches. Section 5 proposes policies designed to alleviate the delayed discharge problem and to reduce bed blocking, comparing them under two different scenarios. Section 6 presents the results of these interventions, and section 7 concludes with some suggestions for future research work.

\section{BACKGROUND}

In the years prior to 2008 Ireland enjoyed one of the highest economic growth rates in Europe, and 
public expenditure rose rapidly - by nearly 40\% - between 2005 and 2008 (HSE 2012b). However, public debt, unemployment and outward migration have subsequently increased sharply. The worsening economic outlook, and the conditions of the financial assistance received from the European Union and the International Monetary Fund, have meant substantial cuts in public spending on health have had to be made (Evetovits et al. 2012).

The total number of closed beds in the Irish health service has spiralled by nearly $40 \%$, in both acute and long-stay beds (Department of Health 2010). The resultant bed shortages have significantly increased EDs overcrowding, with high percentages of patients leaving EDs without being seen at all, and increased mortality rates for elderly patients. Several national reports have highlighted the growing demand for emergency care and - mainly due to the recent economic constraints - the simultaneous decrease in the number of EDs operating to meet those demands. Ireland also still has relatively poorly developed primary and community health services, with two-thirds of the population having to pay the full out-of-pocket costs of their primary care, and a care model that favours hospitals over community services (Evetovits et al. 2012).

Besides limited health care system capacity and cuts in public health expenditures, Ireland has experienced significant population growth (and continues to do so), increasing the demand for care. Elderly people currently constitute around $11 \%$ of the Irish population. In 2012, almost one-third (33.2\%) of total hospital discharges were of elderly patients, a figure that had increased annually by $5 \%$ on average since 2008, and they consumed the highest percentage of total bed-days (47.3\%), an increase of $1.9 \%$ on the 2011 figure (HRID \& ESRI 2013). Projections made in 2002 by the Irish National Council on Ageing and Older People (NCAOP) show that elderly females and males will account for $16.4 \%$ and $14.1 \%$ of the Irish population, respectively, by 2021 (Connell \& Pringle 2004). Figure 1 reveals the increasing trend of older Irish people. Data shows that, relative to both the population as a whole and to the numbers of older people, capacity and service availability have declined (Evetovits et al. 2012). These simple demographic effects have led to a significant rise in the need for long-term care: on the basis of current patterns of community provision, more nursing home places will be required at the rate of around 20\% per year over the next five years (Wren et al. 2012). 


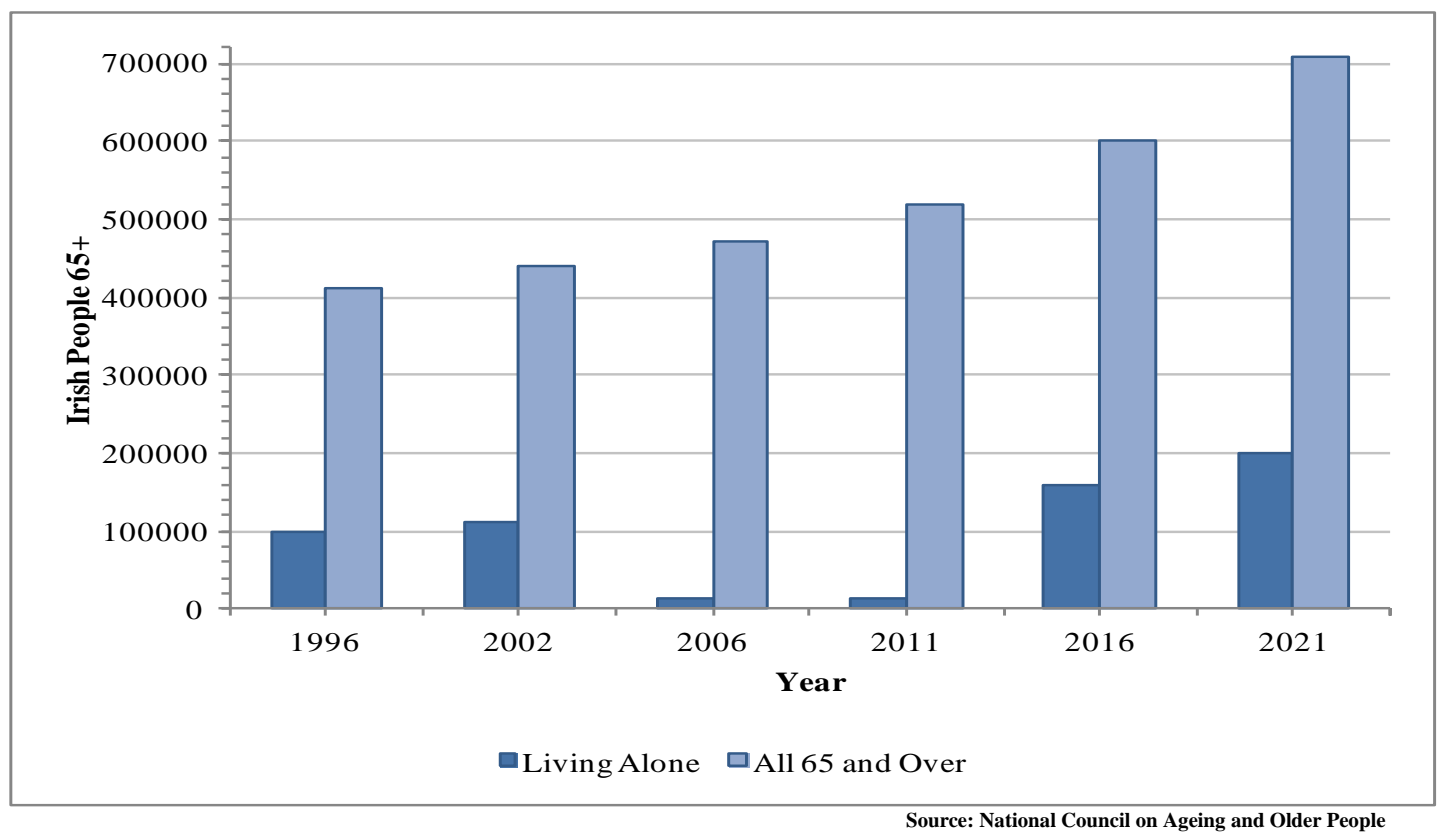

Figure 1: Elderly people in Ireland.

\section{PROBLEM STATEMENT}

Delayed discharge is a term used to describe the situation where, although medically well enough for discharge, patients are unable to leave acute care beds because arrangements for 'step-down' care services have not been completed (Bryan et al. 2006), thus causing them to stay for unnecessarily long periods in acute hospitals (Majeed et al. 2012). Such delayed transfers, which particularly involve older people with complex needs, lead inevitably to a phenomenon known as 'bed blocking', which restricts admissions to acute hospitals. There are several causes of delayed discharges, such as the lack of continuing care, deficiencies in social workers' capacities to carry out patient assessments, etc., but one of the main causes is the shortage of post-acute care beds.

Acute hospital beds are among the most expensive resources in the entire healthcare system, so acute hospitals face substantial costs (Liotta \& Mancinelli 2012), and such problems are intensified when older and dependent patients have to stay in acute beds after their treatment is completed due to shortages in appropriate alternative care provision (Department of Health 2010). Bed blocking means beds cannot be freed up to admit new patients, and causes build-ups in EDs' trolley and treatment lists and leads to inefficiencies in acute bed usage. HSE reports that, in early July 2012, a daily average of 680 Irish patients were awaiting 'step-down' facilities that would allow them to be discharged from acute 
hospitals (HSE 2012a). As acute hospital beds cost up to $€ 850$ a night to run, caring for these 680 delayed patients costs about $€ 0.578$ million a day. The problem of delayed discharges in Ireland has been identified as a national-level issue (HSE 2014; Gallagher et al. 2008), but is not confined to Ireland: it has been reported in the UK, Sweden, Norway, New Zealand and the USA (Vetter 2003; Bryan 2010).

The problem of delayed discharge not only has significant negative cost impacts on the health system, but also has unwanted side effects on the older patients concerned, who are at increased risk of functional decline, social isolation, and loss of independence (Kydd 2008; Covinsky et al. 2003; Bryan 2010). Delayed discharges often have significant ramifications on patient flow throughout the wider healthcare system, causing such negative results as ED overcrowding, high cancelation rates of scheduled procedures, and poor coordination of post-acute and community care resources as well as adversely affecting acute hospitals' abilities to reduce their waiting lists and provide their services efficiently (Majeed et al. 2012). Therefore, the lack of short- and long-term beds for elderly patients awaiting discharge contributes to increase waiting times in many other stages of the healthcare system. These delays, and their influence on overall health system capacities, reflect the underlying mismatch between patients' needs and their access to appropriate health care services (Costa et al. 2012), and have led to greater public disquiet.

The causes of delayed discharges are diverse, ranging from waiting for 'step-down' services to internal hospital delays due to lack of discharge plans, as well as factors related to patients' inability to find carers. The limited capacity in Irish post-acute facilities is one of the key determinants of the current problem. An analysis of the causes for delayed discharge found that $90 \%$ of patients were $65+$, and $75 \%$ of those patients were waiting for nursing home beds (HSE 2012a).

An analysis by the HSE reveals that there was a daily average of 680 delayed discharge patients in Irish hospitals at the beginning of July 2012 (see Table 1). Of them, 44\% (300 patients) had been awaiting 'step-down' facilities for over a month, and 14.6\% (44 patients) had been waiting for six months or more to be discharged. Table 2 shows an HSE analysis of the reasons for the delayed discharges of these 680 patients. It shows that elderly patients accounted for $87 \%$ of all cases of whom 40.7\% were awaiting the outcome of the 'Fair Deal' scheme applications (a nursing home support scheme administered by HSE): $18 \%$ of those patients' Fair Deal applications had not even been 
submitted. $18.8 \%$ of all cases were awaiting home help packages, rehabilitation services, external convalescent care or hospice care to become available.

Table 1: Delayed discharge by time band and HSE Area

\begin{tabular}{|c|c|c|c|c|c|c|}
\hline AREA & $\begin{array}{c}0-2 \\
\text { weeks }\end{array}$ & $\begin{array}{c}\text { 2-4 } \\
\text { Weeks }\end{array}$ & $\begin{array}{c}\text { 4-26 } \\
\text { Weeks }\end{array}$ & $\begin{array}{c}26+ \\
\text { Weeks }\end{array}$ & $\begin{array}{l}\text { Unable to Break } \\
\text { into time Period }\end{array}$ & Total \\
\hline HSE Dublin Mid Leinster Area & 55 & 72 & 92 & 20 & & 239 \\
\hline HSE Dublin/North East Area & 61 & 52 & 134 & 18 & 13 & 278 \\
\hline HSE South Area & 55 & 29 & 23 & 6 & & 113 \\
\hline HSE Western Area & 36 & 7 & 7 & & & 63 \\
\hline Total & 207 & 160 & 256 & 44 & 13 & 680 \\
\hline Source: HSE Delayed Discharge Natio & eport & $012(\mathrm{Hs}$ & 12a) & & & \\
\hline
\end{tabular}

Table 2: Outline of the main reasons for delays in patients being discharged from hospitals.

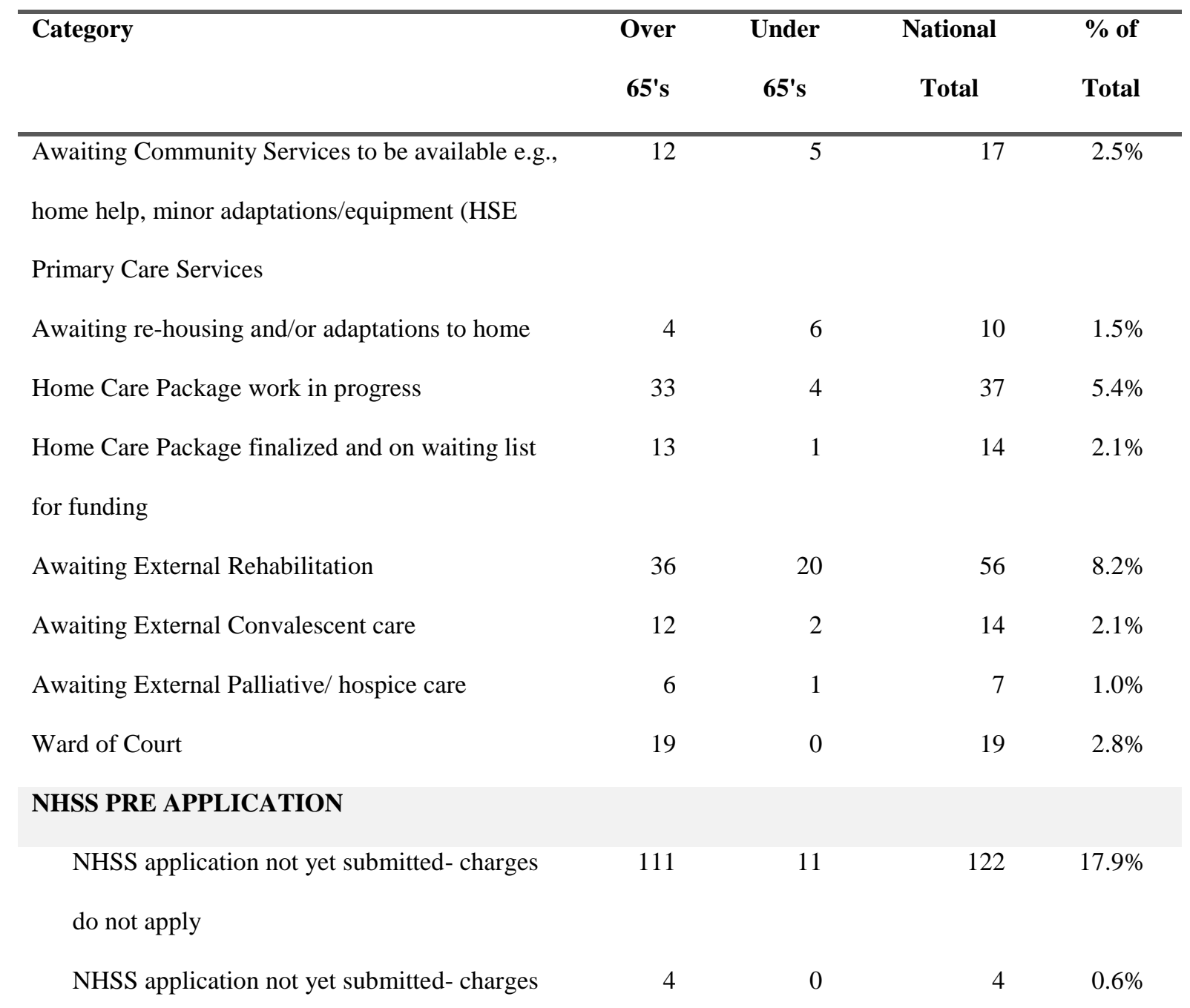


apply

\section{NHSS POST APPLICATION}

HSE determinations in progress- awaiting

outcomes

Funding has been exhausted and the person is

on a waiting list for financial support

Patient awaiting bed due to particular care

requirements

Patient awaiting bed within reasonable

proximity to their home and family

Other compelling reason

HSE determinations complete

Grand Total
257

10

45

25

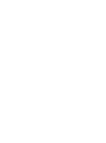

20

277

$40.7 \%$

45

14

59

$8.7 \%$

5

2

27

$4.0 \%$

Source: HSE Delayed Discharge National Report July 2012 (HSE 2012a).

The delayed discharge of clinically well patients to nursing homes and other appropriate facilities represents a significant cost to acute hospitals. It affects patients awaiting emergency and elective care, increasing the numbers on waiting lists and the inappropriate use of trolleys as beds. Based on HSE reports, 680 clinically discharged patients still occupying beds in acute hospitals represents an annual cost of around 248,200 (i.e., $680 * 365$ ) bed days, wasting about $€ 210.7$ million annually. Continued bed closures and restricted bed capacity due to undischarged patients also lead to longer waiting lists, delayed treatment, poorer patient outcomes, increased complications, greater morbidity and ultimately higher health care costs. Acute beds are costly and inefficient bed utilization is a depletion of limited public resources. Unnecessarily lengthy stays in acute hospitals can expose patients to the risk of hospital-acquired infections, and delayed transfer can lead to depression or a decrease in functional independence. Thus policy makers, practitioners and patients all see delayed hospital discharges as problematic for managerial, financial and humanitarian reasons (Glasby 2004). 


\section{LITERATURE REVIEW}

At the end of the 1950s, Professor Jay Forrester introduced System Dynamics (SD) at the Massachusetts Institute of Technology's Sloan School of Management. He brought engineering feedback control principles and methods to management and social science situations, and then applied this approach to any complex system that exhibited dynamic behaviours over time. SD methodology attempts to simulate the system's behaviour over time by representing the causal relationships between its key variables, and is particularly suited to cases of dynamic complexity. The approach supports decision-making processes that can drive system improvement, as well as being useful in improving learning in complex systems.

Business systems exhibit two types of complexity: combinatorial complexity and dynamic complexity (Sterman 2000). Combinatorial (or detail) complexity explains how complex a problem is in terms of alternatives (Cai et al. 1999; Papadimitriou \& Steiglitz 1998), and can be used to represent any combinatorial problem such as staff scheduling (Burke et al. 2008). On the other hand, dynamic complexity describes the nonlinear interactions of system elements over time, and may appear even in very simple systems (Senge 2006; Sterman 2000). System complexity can be caused by the bounded rationality of decision makers or misperceptions and nonlinearity of interactions (Kampmann \& Sterman 1998), and can adversely affect human decision-making processes, resulting in sub-optimal, or even unintended, results (and side effects).

Delay, accumulation and feedback loops are considered ubiquitous characteristics of healthcare systems, which is a strong argument for using system dynamics as a framework for their study (Davies \& Davies 1994). A large number of elements interact in such systems, and impact on each other. Such interactions may be circular and are challenging to capture, so that actions and decisions and their interrelationships may not be immediately apparent or measurable. For example, there will be a delay between when a decision is made (for instance) that a hospital expansion is needed to satisfy demand and when the expanded hospital is fully functioning. Similarly, there will be time delays and variations between when healthcare problems appear and when actions are taken to restore the system to the desired state of being able to meet demand. Furthermore, the existence of nonlinear relationships increases the 
difficulty of predicting healthcare systems' behaviours accurately, and complicates decision-making processes. For example, the relationship between patients' admission waiting times and lengths of stay (LOS) is nonlinear. (Chalfin et al. 2007) have shown that if a patient is admitted immediately, it is likely that their LOS will be short - but, if they have to wait a long time to be admitted, the LOS is likely to be significantly longer. And the patient's state may worsen considerably while waiting for medication, particularly if they are elderly.

SD offers a methodology that can help businesses and government institutions to develop a strategy and analyse policy interventions by modelling causal relationships and feedback systems (Sweetser 1999; Morecroft 1988). The method has been applied to model such strategic aspects of policy and national issues in care systems as patient's pathways (Monefeldt et al. 2000) and planning care for the elderly (Wolstenholme 1999; Walker \& Haslett 2001; Desai et al. 2008). Heidenberger \& Flessa (1993) developed a system dynamics model for AIDS policy support in Tanzania that captured the complex behaviour of the epidemics while illustrating the medical and some economic consequences. A system dynamics model has been developed for healthcare in Alberta, Canada (Cooke et al. 2007) to evaluate health policies for emergency services. In the same hospital, Robertson, Bloom, \& Duckett, 2012 (2012) has developed an interactive model for planning the workforce for healthcare based on system dynamics. System dynamics also has been used for mapping of acute patient flows for NHS in England (Lane \& Husemann 2007). Masnick \& McDonnell (2010) applied system dynamics modelling to link clinical workforce requirements to the clinical workforce workload. Their model produced the broad of healthcare that helps human resource planners to improve the decision-making process. The consequences of policies intended to restore the performance of healthcare systems to their desired state may be disappointing: explanations may include staff resistance to new policies and counter-intuitive behaviour on the part of the policymakers. Simulation and modelling can be useful and flexible tools to tackle several of these concerns and to contribute towards improved health system performance and thus better health care provision.

\section{MODEL CONCEPTUALISATION AND FORMULATION}

The most challenging elderly patients are those referred to as 'frail' patients, who are suffering from 
an array of medical conditions that individually may be treatable, but which, collectively, create complex and potentially overwhelming medical burdens (McDermid \& Bagshaw 2011). They account for $18-20 \%$ of elderly admissions, and generally need longer treatment in healthcare facilities followed by extended rehabilitation or community care. Adhering to the LOS-based cut-off point set by Irish healthcare executives, frail patients are characterized in this study as those whose LOS in an acute hospital exceeds 15 days. The remaining 80-82\% of elderly patients (who experienced shorter LOS) are referred to as non-frail.

\subsection{Conceptualising Elderly Patients' Care Pathways}

Patients come to hospitals from their surrounding communities in two groups: elective and emergency: this study focuses on the latter group. The journey of an elderly emergency patient through the hospital system usually begins with their arrival at the ED by ambulance, as 'walk-ins', by referral from a General Practitioner (GP) or from another hospital. The reasons that affect the pattern of patient arrivals to acute hospitals are beyond the scope of this study - so arrival rate to acute hospitals is considered exogenous to our model. New emergency patients' admission rates are regulated by hospitals' bed management teams. Shortages of available hospital beds create delays in patients' admissions from EDs. Thus, incorporating bed occupancy rates (i.e., the ratio between occupied beds and total bed capacity) in the model is crucial. After admission, elderly patients receive treatment in acute beds until they are assigned a care pathway subject to their assessments and frailty levels. Their treatment periods range from a few days to two weeks for non-frail patients, but may often be longer for frail patients. The hospital's discharge rate will change its acute bed occupancy levels, and also relates to patients' LOS. Various factors determine elderly patients' LOS in acute hospitals, such as their medical profiles, the quality of the service and the availability of post-acute care capacity. After their stay, they are assessed for discharge. Figure 2 illustrates their flow and alternative care pathways: the thickness of the arrows reflect the density of the flows.

After their stays, patients are discharged to one of the following destinations:

- Another Acute Hospital: Certain medical procedures may require equipment that is unavailable in the acute hospital where an elderly patient was first admitted, so they need to be 
transferred to another hospital where it is available. Discharge figures to other hospitals include patients who are moved to undergo certain procedures, and those who are returned to their original hospital after such procedures.

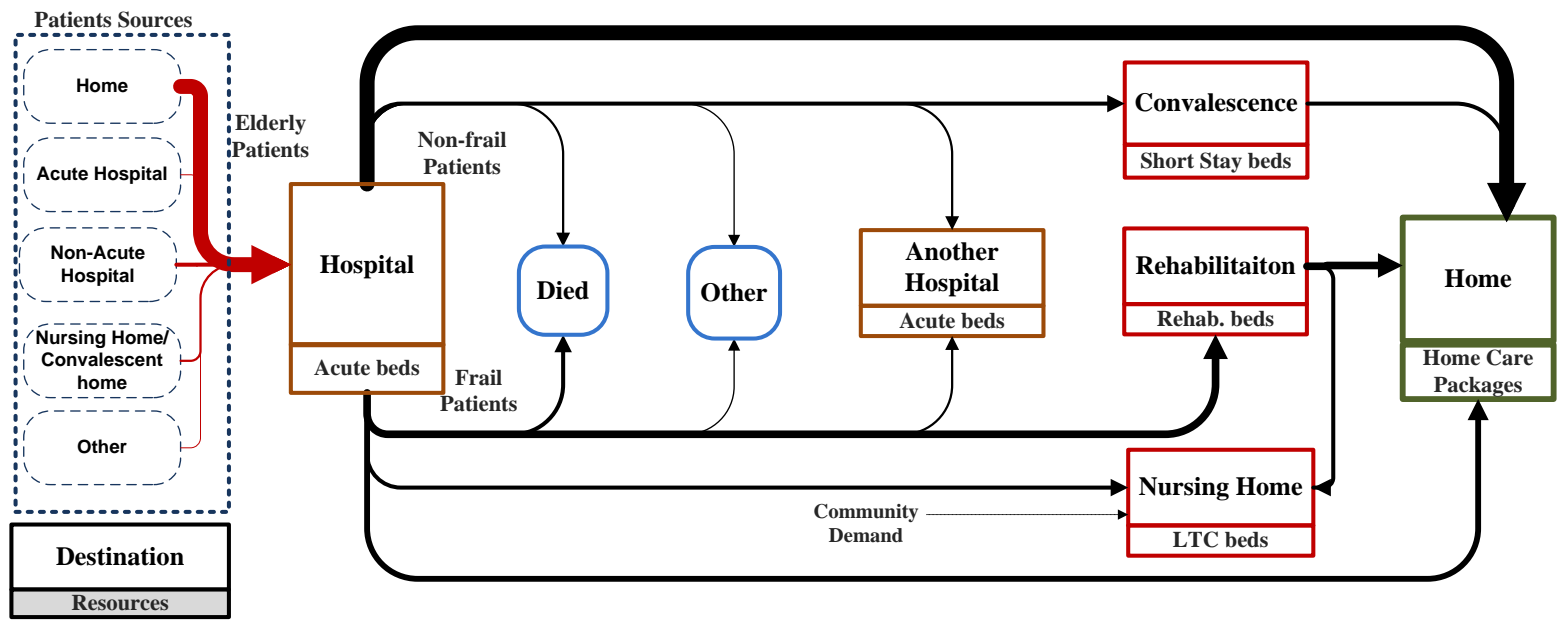

Figure 2: Conceptual elderly patients' pathways diagram

- Rehabilitation: Patients who are assessed as having the potential to improve towards functional independence are discharged to an on- or off-site facility where they can receive rehabilitation care. Such services can be seen as intermediate destinations, suited to the fact that they are no longer categorized as acutely ill, but still need close medical observation as they recover (Katsaliaki et al. 2005). After such rehabilitation, the vast majority of patients are discharged home, and those who have not recovered to long-term care.

- Convalescence: A few patients are discharged to convalescent care facilities for short periods (or, in some cases, to dedicated short-stay beds in nursing homes) to recover from medical procedures. These offer less intensive care than rehabilitation, as they mainly prepare patients to go home.

- Long Term Care (LTC): More than a quarter of frail elderly patients will be unable to live alone at their homes as they are no longer able to care for themselves, and may require ongoing medical supervision. Such patients are discharged to public or private nursing homes to receive LTC, where they often remain for long periods (i.e., over a year). Such prolonged stays hinder the supply of LTC beds in the healthcare system, and waiting times can amount to several months. In addition to hospital demand, there are also frail patients in the community who need LTC, and must wait at home for nursing home places to become available. 
- Home: The vast majority of non-frail elderly patients are eventually discharged to their homes, some directly, or after a short stay in convalescence, or a period of rehabilitation. More than half of them will continue to require medical care in their own homes, and are given Home Care Packages (HCP), a set of state-provided services that may include home help, nursing, physiotherapy, occupational therapy and other services. Home helps provide domestic services (cleaning, shopping, doing laundry and making meals, etc.), and some provide personal care and companionship (Barrett et al. 2011). The HCP may comprise paramedical, nursing, respite, home help or other services based on the applicant's needs.

- Other Destinations: In addition to these destinations, a small percentage of elderly patients may die during their acute stay (with the probability of mortality increasing in proportion to their frailty), and another (slightly smaller) number of patients with special conditions are discharged to 'other' destinations (e.g. prisons, psychiatric facilities, etc.).

\subsection{Causal Loops/Dynamic Hypothesis}

The model assumes that, once a patient is admitted to one of the main pools (an acute hospital or post-acute care), s/he will occupy a bed in that pool, staying for a number of days before being either transferred to the other pool or discharged from the health service facility. This period represents their length of stay (LOS) in the health service facility. In terms of bed demand, this model assumes that a finite number of beds (bed capacity) are available in each pool, and that, if patient numbers exceed the beds available there, they will 'stack up' in the ED.

The model also assumes that current patterns of care needs and health status will persist over time, suggesting that elderly people in the future will have identical health status to those in the base year (2010) - although this may be in dispute if recent health trends are maintained. Elderly patients' health has been generally improving due to advances in technology and medication, and they are currently healthier than they were two decades ago (Crimmins 2004). At the same time, the increasing prevalence of some diseases such as diabetes and obesity among young people suggests that future elderly cohorts might even be less healthy (Lakdawalla et al. 2004). The future of these trends are unclear, and it is 
difficult to predict their consequences and effects (Goldman et al. 2005). It is believed that the assumption of the persistence of current trends is valid, because running scenarios for six years is not a long enough period to witness significant changes in demography or in the current status of medical needs and health.

A causal loop diagram (CLD) uses causality relationships and feedback loops to provide a general structure of a problem to be examined. A CLD is a qualitative method designed to capture the causes of dynamic hypothesis to help policy and decision-makers understand a problem's complexity by interpreting the feedback loops. A causal diagram consists of key variables linked by arrows indicating the causal influences. Each link (arrow) connects two variables - an independent variable (at the tail of the arrow) and a dependent variable at its head. A polarity ('+' or '-') is assigned to each link denoting the influence of the independent variable on the dependent variable - these polarities describe the structure of the system, not the behaviours of the variables. CLD differentiates between two types of feedback loops - reinforcing and balancing loops. Reinforcing loops are that reinforce the exponential growth or collapse, while balancing (or self-correcting) loops are those which oppose and counteract change. Balancing loops behave in a 'goal seeking' fashion, with goals being implicit or explicit.

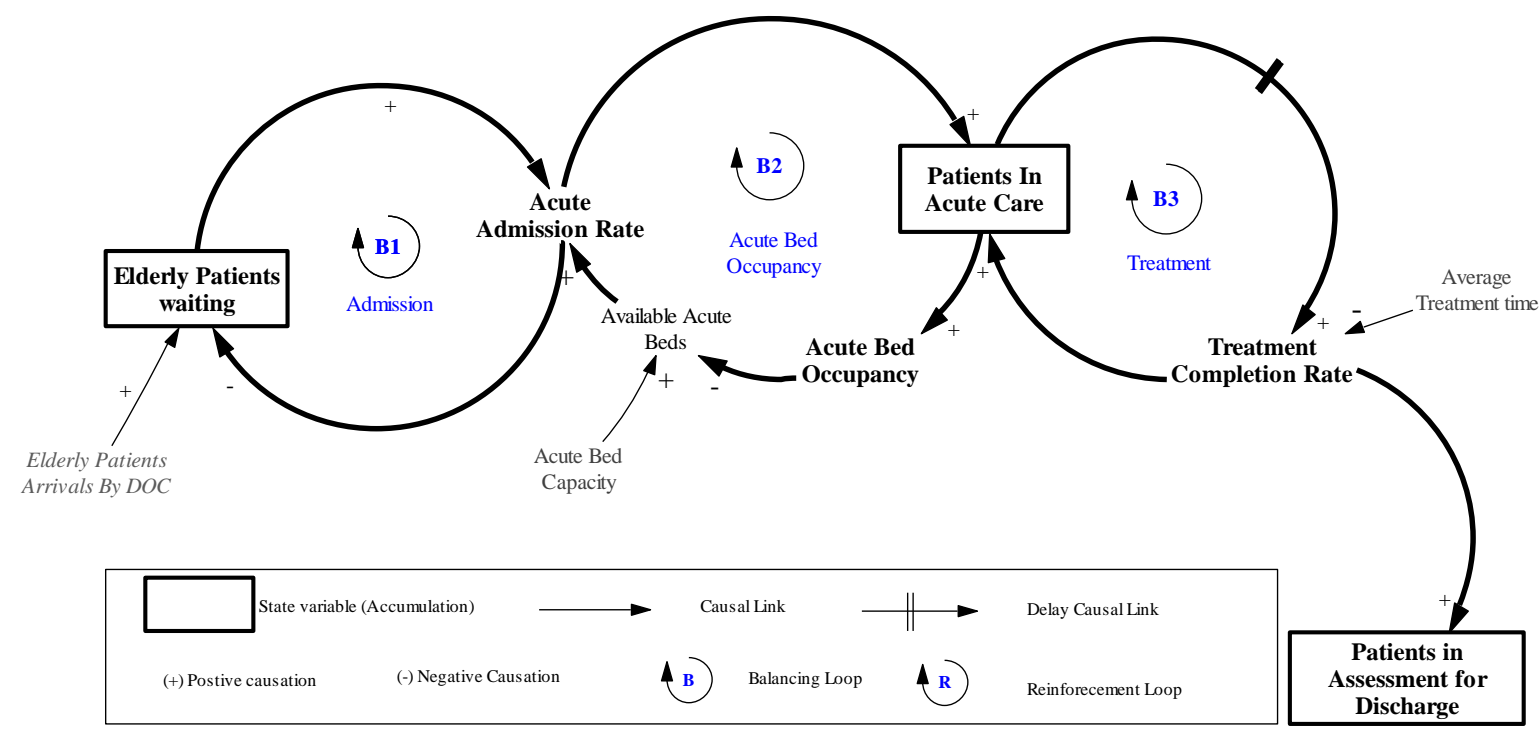

Figure 3: Causal loop diagram for patient flow in acute care. 
The structural causes of the delays in elderly patient discharges are complex. The purpose of using a CLD is to identify the key causes of such delays. From a system thinking perspective, identifying the problem structure is quite complex and entails taking a holistic system view to counter the adverse effects of policy resistance. Figure 3 depicts the CLD for acute admission and treatment processes.

The arrival of elderly patients is assumed to be exogenous at the initial entry to the model. Once an elderly patient has registered in a hospital, s/he waits for admission. The numbers of patients waiting in EDs for admission are increased by their arrival rate and decreased by the acute admission rate. Loop B1 works to reduce the number of waiting patients by admitting them to hospital wards. Assuming there are available acute beds, the number of patients waiting increases the acute admission rate. Available acute beds are the difference between acute bed capacity and acute bed occupancy. Loop B1 aggregates the flow of patients within acute care until they are eventually admitted. Loop B2 shows that admission to hospital wards is limited by the acute bed capacity, which restricts admissions unless there are free resources. Both B1 and B2 loops are balanced feedbacks, whose goal is to lessen the number of waiting patients without exceeding the bed capacity. Following surgical or medical treatment episodes in acute care (loop B3), patients will be assessed for discharge to different destinations.

While patients are waiting for assessment, they are still occupying acute beds (Figure 4), so bed occupancy levels remain unchanged (balancing loop B4). Moreover, patients who have been assessed as needing alternative care (e.g., rehabilitation, convalescence, LTC, etc.), but are still waiting for such services, are also still occupying acute beds (balancing loop B5). Thus patients in both the 'Assessment for Discharge' or 'Waiting for Post-Acute Care' states contribute to blocking acute beds, limiting other patients' access to healthcare systems, so explaining the mismatch between patients' needs and access to appropriate healthcare services, and delineating the quality of the whole healthcare system. 


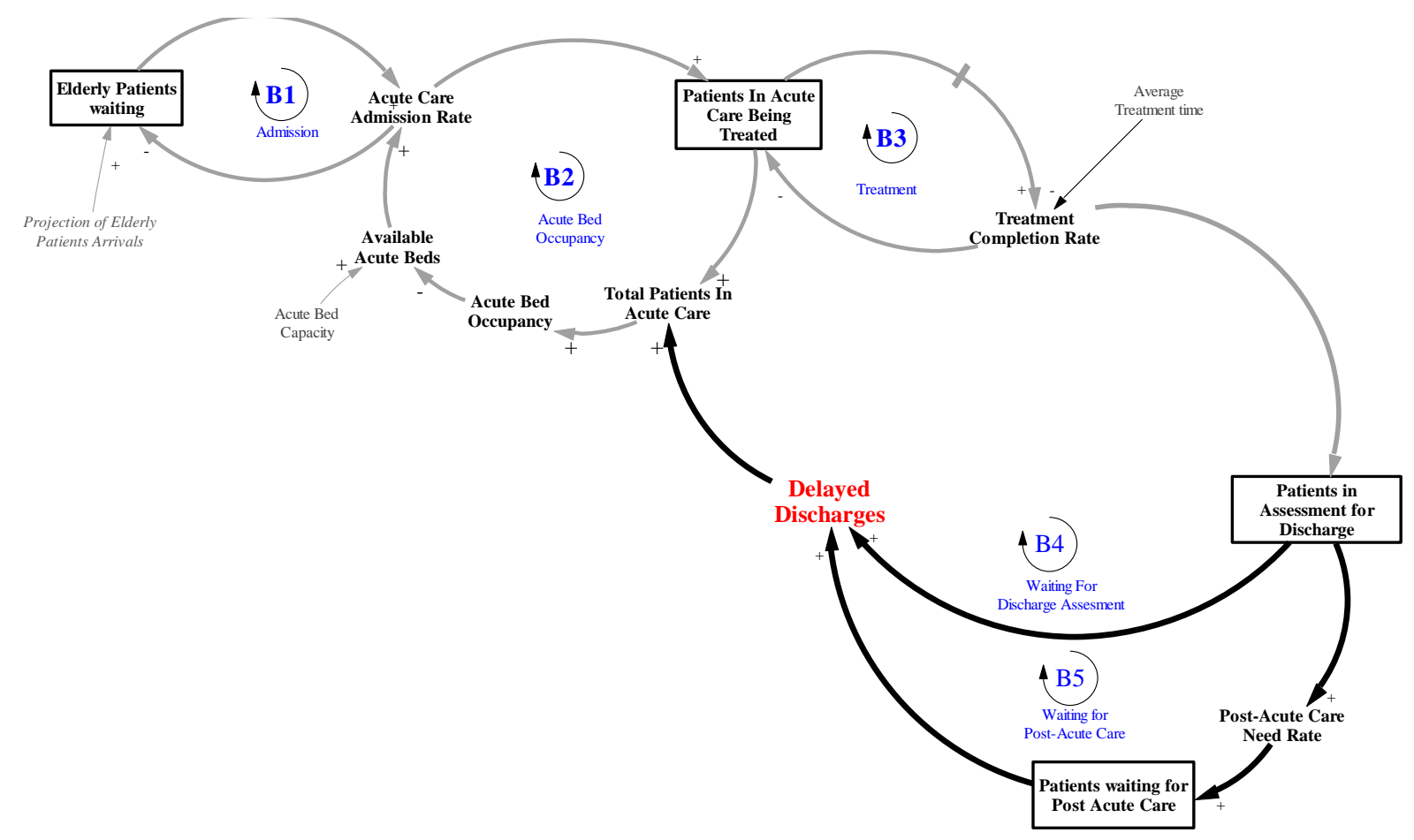

Fig 4: Causal loop diagram for main causes of delayed discharge.

The reinforcement loops (R1 and R2), on the other hand, tend to reinforce or amplify whatever is occurring in the system (Figure 5). As more patients are discharged from hospitals, more acute beds become available, so more new admissions can occur. Reinforcing feedback loops get things moving as they build up momentum. Loop R1 acts to discharge patients who do not need alternate care destinations (e.g., home, death, or other destination). More available beds in post-acute care reduce number of delayed discharge patients who are waiting in hospitals for post-acute care (loop R2). This loop is an essential loop as it works to release the blocked acute beds. If more patients are discharged from post-acute care the number of free post-acute beds increases, so more new patients can be discharged from acute care and admitted to post-acute care. This loop also acts to diminish the postacute waiting list. However, the post-acute bed occupancy loop (B7) confines the admissions to postacute care according to bed capacity. (For simplicity reasons, the model groups all post-acute care services together.) By restricting - or even shutting down - post-acute admissions, loop B8 ensures that patients are not admitted until/unless there are available beds. As the post-acute care discharge rate rises, the post-acute bed occupancy level decreases, freeing up beds for new admissions (loop R3). 


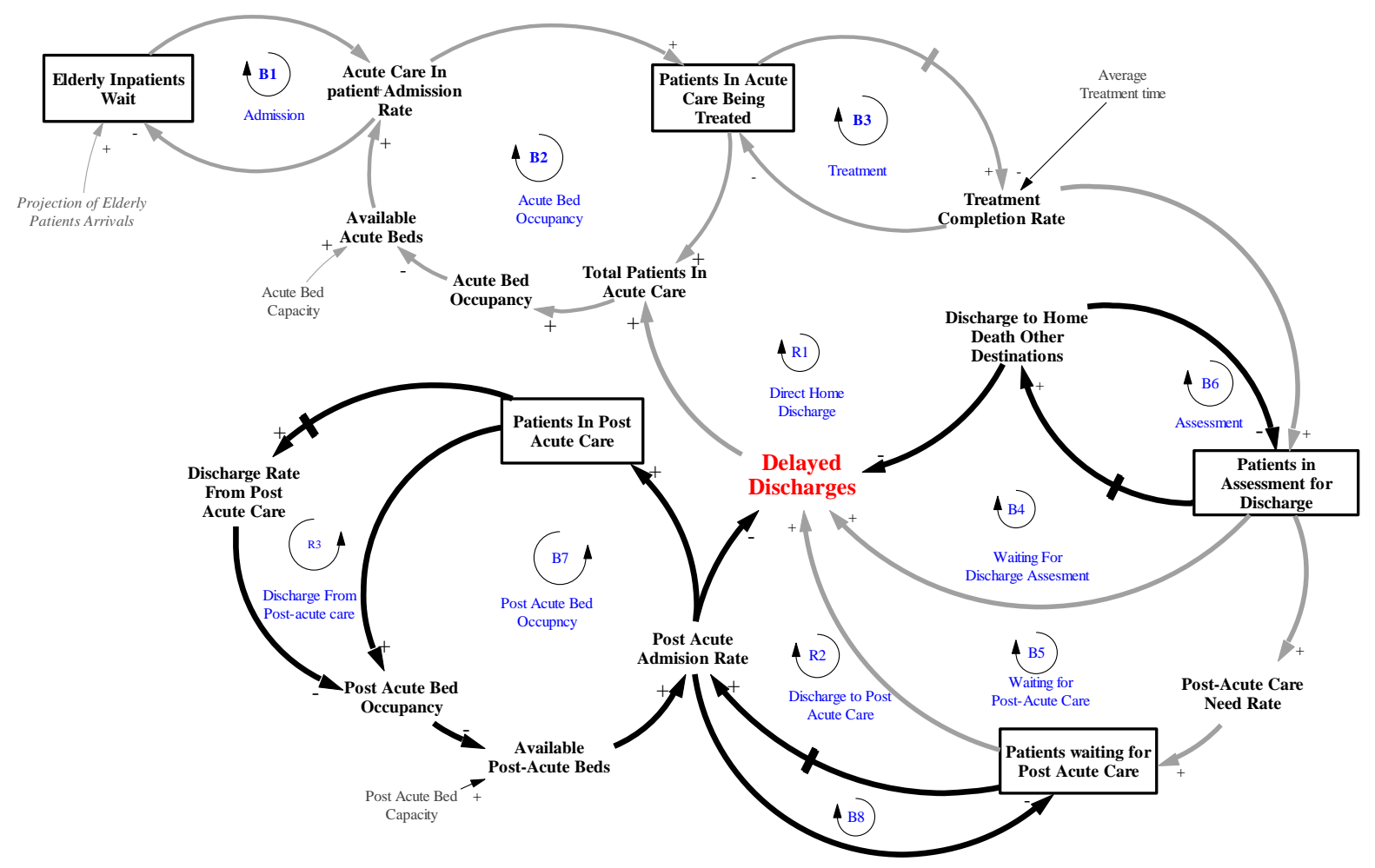

Fig 5: A simplified causal loop diagram for the flows of elderly patients in the Irish healthcare system.

\subsection{Simulation Model}

A Causal Loop Diagram can be a very useful tool to describe interdependencies and feedback processes, but it suffers from some limitations in other respects. Its primary shortcoming is its inability to capture the quantitative aspects of the system (stocks and flows). Besides feedback mechanisms, dynamic system theory consists of two central concepts: stocks and flows. Stocks (i.e., state variables) are the accumulations that characterize the system's state and provide the information on which to base actions. Figure 6 exhibits a simplified stock and flow structure representing the causal loop diagram given in Figure 5. Stocks are variables that describe the state of the system - in this case, they represent the accumulation of patients in the healthcare system, and are depicted by rectangles. Flow variables are rates or control variables that can change the state (i.e., the stocks) of the system. The model in Figure 6 depicts the main elderly inpatient pathways through acute hospitals and onwards into postacute care facilities. The double lines depict the flow of elderly patients through the model from one state to another. Inflows are portrayed by pipes pointing into (i.e., adding to) the stocks: outflows are 
shown by pipes pointing out from (i.e., deducting from) stocks. The flow variables are maintained by valves, which act as regulators to control the rate of flow of patients from a source to a destination state. The cloud symbol indicates a source or destination outside the model's boundaries (i.e., beyond its scope). For simplicity of presentation, the stock and flow diagram of the capacities for both acute and post-acute are separated into different diagrams in Figure 7.

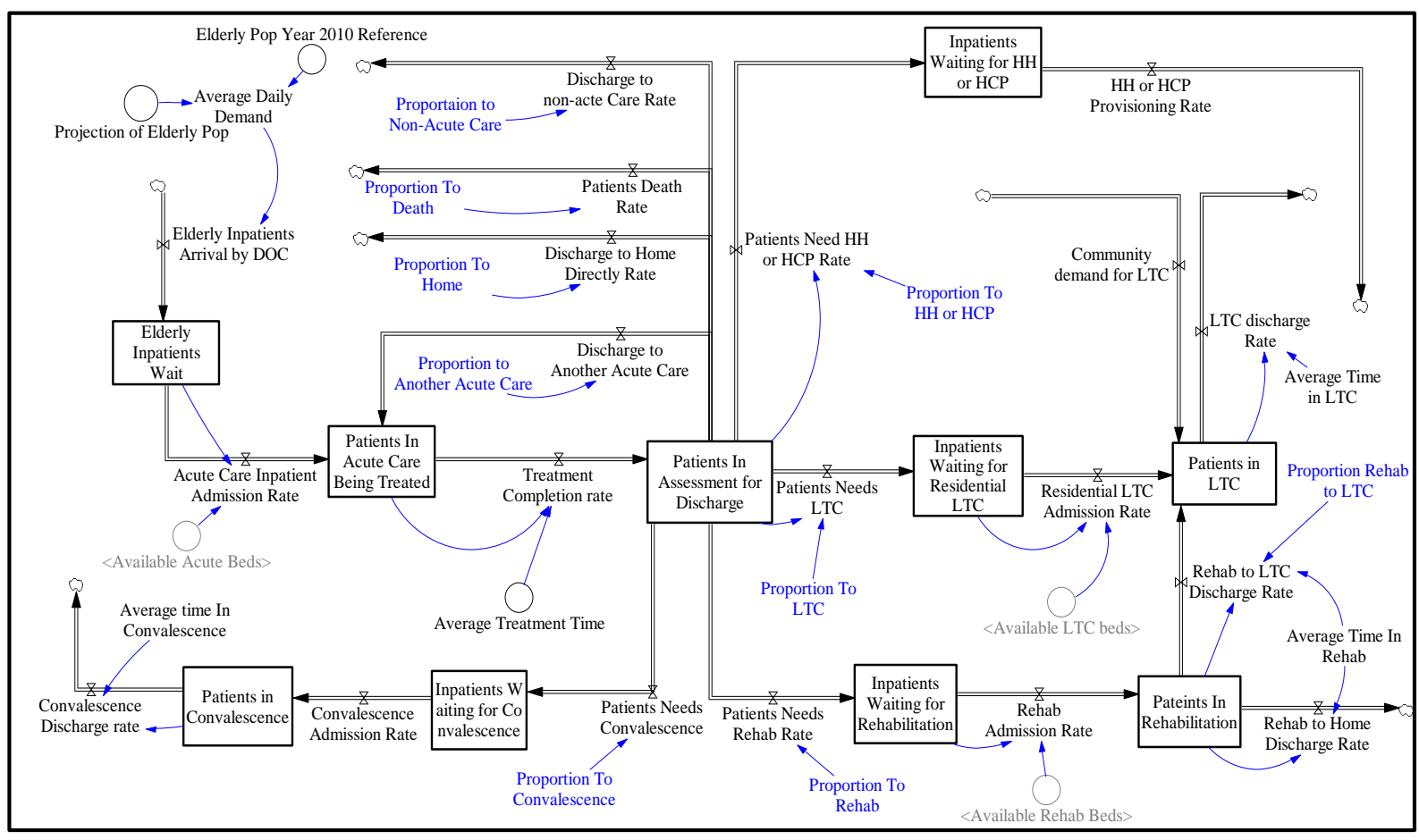

Figure 6: Stock and flow Map showing the medical older inpatient pathways through the Irish Healthcare system. 


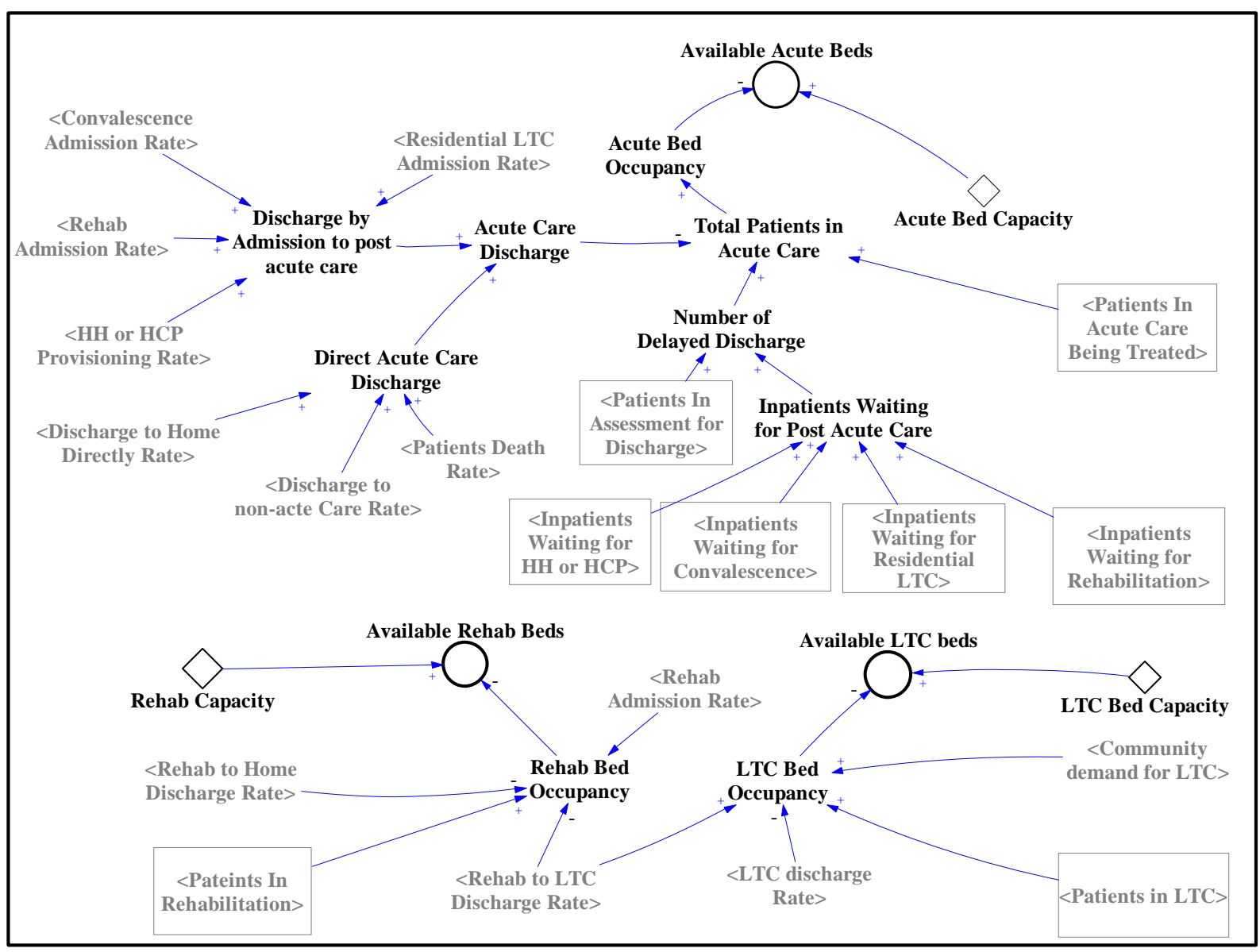

Figure 7: Map showing the capacity templates of both acute and post-acute care.

\subsection{Mathematical Formulations}

Mathematically, SD models can be described as a set of integral equations which represent the accumulated stocks or integrated net flows. A general mathematical representation of stocks and flows can be given by the following equations:

$$
\begin{gathered}
\operatorname{Stock}(t)=\int_{t_{0}}^{t}[\operatorname{inflow}(t)-\operatorname{outflow}(t)] d t+\operatorname{Stock}\left(t_{0}\right) \\
\operatorname{Inflow}(t)=f(\operatorname{Stock}(t), A(t), P) \\
\operatorname{Outflow}(t)=\mathrm{g}(\operatorname{Stock}(t), A(t), P)
\end{gathered}
$$

where $A(t)$ are auxiliary variables and $P$ are the system parameters. The flows are a mathematical function of their stocks, other auxiliary variables and system parameters. Inflows and outflows usually 
differ, as they are governed by different decision rules (i.e., $f(\cdot)$ and $g(\cdot)$ ). As a result, stocks create disequilibrium dynamics as they decouple rates of flow.

Model variables including stocks, flows and auxiliaries are functions of time $t$, and their time dependency is explicitly noted in the formulations. The index $i$ is used to indicate patients' groups based on the degree of complexity of their needs. To simplify the model formulation, Table 3 provides abbreviation and notations for variables and parameters used in the model.

\section{Table 3: Notation list}

\begin{tabular}{|c|c|}
\hline Notation & Term \\
\hline$i$ & Elderly patient type $i$ where $i$ can be frail or non-frail. \\
\hline$j$ & Index number of different healthcare services, $j \in J$, and $J=\{a, h c, l, r, c\}$, where $a$ for acute care, $h c$ for Home \\
\hline & Help or Home Care Package (HH or HCP), $l$ for LTC, $r$ for Rehab and $c$ for convalescence. \\
\hline$k$ & $\begin{array}{l}\text { Index number of discharge destination, } k \in K \text {, and } K=\{a, d, h, n, o\} \text {, where } a \text { for another acute hospital, } d \text { for } \\
\text { death, } h \text { for home, } n \text { for non-acute hospital, and } o \text { for other destinations. }\end{array}$ \\
\hline$P_{i}(t)$ & Elderly patients of type $i$ waiting for admission at time $t$. \\
\hline$d_{i}(t)$ & Demand arrival of $i$ at time $t$. \\
\hline$A_{i}^{j}(t)$ & Admission rate of patient type $i$ at time $t$ to a healthcare service $j$. \\
\hline$H_{i}(t)$ & Inpatients of type $i$ in acute care being treated at time $t$. \\
\hline$B(t)$ & Number of available acute beds at time $t$. \\
\hline$T C_{i}(t)$ & Treatment competition rate of patient type $i$ at time $t$. \\
\hline$T_{i}$ & Average treatment time in acute care of patient type $i$. \\
\hline$S_{i}(t)$ & Inpatients of patient type $i$ being assessed at time $t$ for discharge. \\
\hline$O_{i}^{d}(t)$ & Number of patients of type $i$ discharged directly from acute care at time $t$ without a need to post-acute care. \\
\hline$O_{i}^{p}(t)$ & Number of patients of type $i$ that need a post-acute service at time $t$. \\
\hline$\lambda_{i}^{k}$ & Proportion of patients of type $i$ discharged from acute care to a destination $k$. \\
\hline$\beta_{i}^{j}$ & Proportion of patients of type $i$ needing a post cute-care service $j$. \\
\hline$D_{i}^{k}(t)$ & Discharge rate from acute care to a destination $k$ of patient type $i$ at time $t$. \\
\hline$N_{i}^{j}(t)$ & Rate of patients of type $i$ needing a post-acute service $j$. \\
\hline$\delta_{i}$ & Proportion of patients of type $i$ discharged to LTC after finishing rehabilitation care. \\
\hline$U^{j}$ & Bed capacity in healthcare service $j$, where $j \in J \backslash\{h c, c\}$. \\
\hline
\end{tabular}




\begin{tabular}{ll}
\hline$B(t)$ & Number of available acute beds at time $t$. \\
$K(t)$ & Number of available LTC beds at time $t$. \\
$M(t)$ & Number of available Rehabilitation beds at time $t$. \\
$T_{i}$ & Average treatment time of patient type $i$. \\
$V_{i}^{j}$ & Average length of stay of patient type $i$ in post-acute service $j$, where $j \in J \backslash\{a, h c\}$ \\
$W_{i}^{j}$ & Average waiting time of patient type $i$ to access post-acute service $j \in J \backslash\{, r, l\}$. \\
$Q_{i}^{j}(t)$ & Inpatients of type $i$ waiting for post-acute service $j$ at time $t$. \\
$L_{i}(t)$ & Patients in LTC being served of type $i$ at time $t$. \\
$R_{i}(t)$ & Patients in rehabilitation being served of type $i$ at time $t$. \\
$C_{i}(t)$ & Patients in convalescence being served of type $i$ at time $t$. \\
$D D(t)$ & Number of delayed discharge patients of patient type $i$ at time $t$. \\
\hline
\end{tabular}

Elderly patients' journeys start when they arrive at the hospital's ED. New arrivals $d_{i}(t)$ of each type $i$ patient arrive at any time $t$ and wait for admission. The total number of patients waiting for admission at time $\mathrm{t}$ is given by the following state and flow equations:

$$
\begin{gathered}
P_{i}(t)=\int_{t_{0}}^{t_{f}}\left(d_{i}(t)-A_{i}^{a}(t)\right) d t+P_{i}\left(t_{0}\right) \\
d_{i}(t)=f(\text { demand projection }) \\
A_{i}^{a}(t)=\left\{\begin{array}{cl}
\min \left(B(t), P_{i}(t)\right), & \min \left(B(t), P_{i}(t)\right)>0 \\
0, & \text { Otherwise }
\end{array}\right.
\end{gathered}
$$

where $A_{i}^{a}(t)$ is the admission rate to acute care at time $t$. Patients stay waiting in $\operatorname{ED}\left(P_{i}(t)\right)$ - some of them on trolleys - until they are admitted to acute care $\left(H_{i}(t)\right)$. The total number of inpatients of type $i$ being treated in acute hospitals at time $t$ is defined by equations (7) and (8):

$$
\begin{gathered}
H_{i}(t)=\int_{t_{0}}^{t_{f}}\left(A_{i}^{a}(t)-T C_{i}(t)\right) d t+H_{i}\left(t_{0}\right) \\
T C_{i}(t)=\frac{H_{i}(t)}{T_{i}}
\end{gathered}
$$


Inpatients whose treatment in the acute hospital has been completed at time $t\left(T C_{i}(t)\right)$ wait for discharge assessment. After they have been assessed, they are divided into two main groups according to the discharge assessment decision. The first group $\left(O_{i}^{d}(t)\right)$ are those who are discharged directly from acute care without the need for post-acute service. Direct discharge destinations include: home $\left(D_{i}^{h}(t)\right)$, a non-acute hospital $\left(D_{i}^{n}(t)\right)$, another acute hospital $\left(D_{i}^{a}(t)\right)$, death $\left(D_{i}^{d}(t)\right)$ and other destinations $\left(D_{i}^{o}(t)\right)$. The second group $\left(O_{i}^{p}(t)\right)$ are patients of type $i$ who need post-acute care at time $t$, and includes patients who need $\mathrm{HH}$ or $\operatorname{HCP}\left(N_{i}^{h c}(t)\right), \operatorname{LTC}\left(N_{i}^{l}(t)\right)$, rehabilitation $\left(N_{i}^{r}(t)\right)$, or convalescence $\left(N_{i}^{c}(t)\right)$, although they often have to wait for such services to become available. The following equations represent the total number of inpatients being assessed for discharge at time t:

$$
\begin{aligned}
S_{i}(t)=\int_{t_{0}}^{t_{f}}\left(T C_{i}(t)\right. & \left.-\frac{O_{i}^{d}(t)-O_{i}^{p}(t)}{A T A_{i}}\right) d t+S_{i}\left(t_{0}\right) \\
O_{i}^{d}(t) & =\sum_{k} D_{i}^{k}(t) \\
& =S_{i}(t) \cdot \sum_{k \in K} \lambda_{i}^{k} \\
O_{i}^{p}(t) & =\sum_{j \in J /\{a\}} N_{i}^{j}(t) \\
& =S_{i}(t) \cdot \sum_{j \in J /\{a\}} \beta_{i}^{j}
\end{aligned}
$$

where $A T A_{i}$ is the average time taken to assess a patient of type $i$ for discharge. Parameters $\lambda_{i}^{k}$ and $\beta_{i}^{j}$ are proportions of patients discharged from acute care, such that $\sum_{i}\left(\sum_{k} \lambda_{i}^{k}+\sum_{j} \beta_{i}^{j}\right)=1$. After being assessed for discharge, those patients who need post-acute care $\left(O_{i}^{p}(t)\right)$ wait for it to become available. Since they have limited capacity, these services delay patients' discharges, restricting the effectiveness of the hospital services. The admission rate to these services is constrained by their capacity and patients' average LOS. Equation (12) gives the number of patients waiting for post-acute care at time $t$. 


$$
\begin{gathered}
Q(t)=\sum_{i} \sum_{j \in J /\{a\}} Q_{i}^{j}(t) \\
Q_{i}^{j}(t)=\int_{t_{0}}^{t_{f}}\left(N_{i}^{j}(t)-A_{i}^{j}(t)\right) d t+Q_{i}^{j}\left(t_{0}\right)
\end{gathered}
$$

where $Q_{i}^{j}(t)$ is the number of patients waiting for a post-acute service $j \in J /\{a\}$, and $A_{i}^{j}(t)$ is the admission rate to that service. The total number of delayed discharges includes both the patients waiting for discharge assessment $\left(S_{i}(t)\right)$ and patients waiting for a post-acute service $(Q(t))$. Formally, the total number of patients who are experiencing delayed discharges at time $t$ can be defined as:

$$
D D(t)=Q(t)+\sum_{i} S_{i}(t)
$$

Post-acute admissions $\left(A_{i}^{j}(t)\right)$ reduce delayed discharge numbers. Patients' admission rates for rehabilitation, convalescence, LTC, and HH-HCP are presented by equations (15)-(18), respectively.

$$
\begin{gathered}
A_{i}^{r}(t)=\left\{\begin{array}{cl}
\min \left(Q_{i}^{r}(t), M(t)\right), & \min \left(Q_{i}^{r}(t), M(t)\right)>0 \\
0, & \text { Otherwise }
\end{array}\right. \\
A_{i}^{l}(t)=\left\{\begin{array}{cl}
\min \left(Q_{i}^{l}(t), K(t)\right), & \min \left(Q_{i}^{l}(t), K(t)\right)>0 \\
0, & \text { Otherwise }
\end{array}\right. \\
A_{i}^{c}(t)=\frac{Q_{i}^{c}(t)}{W_{i}^{c}} \\
A_{i}^{h c}(t)=\frac{Q_{i}^{h c}(t)}{W_{i}^{h c}}
\end{gathered}
$$

where $M(t)$ and $K(t)$ are the available bed capacity in rehabilitation and LTC respectively, while $W_{i}^{c}$ and $W_{i}^{h c}$ are the average waiting times to access convalescence and HH-HCP services. Due to data unavailability for the convalescence and HH-HCP healthcare service bed capacities, the average waiting times to access such services is used to estimate their admission rate. At any point in time, the total number of patients being treated in rehabilitation, convalescence and LTC can be defined mathematically by the following state equations:

$$
R_{i}(t)=\int_{t_{0}}^{t_{f}}\left(A_{i}^{r}(t)-\frac{R_{i}(t) \cdot \delta_{i}}{V_{i}^{r}}-\frac{R_{i}(t) \cdot\left(1-\delta_{i}\right)}{V_{i}^{r}}\right) d t+R_{i}\left(t_{0}\right)
$$




$$
\begin{gathered}
C_{i}(t)=\int_{t_{0}}^{t_{f}}\left(A_{i}^{c}(t)-\frac{C_{i}(t)}{V_{i}^{c}}\right) d t+C_{i}\left(t_{0}\right) \\
L_{i}(t)=\int_{t_{0}}^{t_{f}}\left(A_{i}^{l}(t)+\frac{R_{i}(t) \cdot \delta_{i}}{V_{i}^{r}}-\frac{L_{i}(t)}{V_{i}^{l}}\right) d t+L_{i}\left(t_{0}\right)
\end{gathered}
$$

where $V_{i}^{j}$ is the average length of stay of patient type $i$ in post-acute service $j$, and $\delta_{i}$ is the proportion of patients needing LTC after their rehabilitation has been completed. These services also have limited capacities, which control their admission rates and hence restrict the effectiveness of acute care. The capacities available for rehabilitation, convalescence and acute care are given by equations (22)-(24) respectively:

$$
\begin{gathered}
M(t)=U^{r}+\sum_{i}\left(-R_{i}(t)-A_{i}^{r}(t)+\frac{R_{i}(t) \cdot}{V_{i}^{r}}\right) \\
K(t)=U^{l}+\sum_{i}\left(-L_{i}(t)-\frac{R_{i}(t) \cdot \delta_{i}}{V_{i}^{r}}+\frac{L_{i}(t)}{V_{i}^{l}}\right) \\
B(t)=U^{a}-D D(t)+\sum_{i}\left(-H_{i}(t)-O_{i}^{p}(t)+O_{i}^{d}(t)+\sum_{j \in J\{a\}} A_{i}^{j}(t)\right)
\end{gathered}
$$

Four performance indicators are used to measure policy interventions and compare model runs. First, the number of delayed discharges indicator (i.e., the total daily number of patients who are being assessed for discharge or waiting for post-acute services) is given by equation (14). Second, the bed blocking percentage is the proportion of the total number of delayed discharges to the hospital's bed capacity, which can be represented mathematically by dividing the number of delayed discharges by the acute bed capacity $\left(D D(t) / U^{a}\right)$. Third, the $A L O S$ indicator is the average treatment time added to the total waiting time for discharge assessment and post-acute admission: ALOS at time $t$ can be formally expressed by equation (25):

$$
\operatorname{ALOS}(t)=\sum_{i}\left(T_{i}+A T A_{i}+\sum_{j \in J /\{a\}}\left(\frac{A_{i}^{j}(t)}{Q_{i}^{j}(t)}\right)\right)
$$

The third term in equation (25) is the average waiting time in post-acute care, which can be denoted by 
dividing the number of admissions for post-acute care $\left(A_{i}^{j}(t)\right.$ by the number of patients waiting for such services $Q_{i}^{j}(t)$. Finally, post-acute accessibility is the percentage of post-acute needs that are met to the total demand for post-acute care within the time frame (i.e., 60 days): it measures the proportion of patients who actually receive post-acute care within a two month waiting period to the number who need this service.

\subsection{Model Calibration}

This model typically runs over a year on a daily basis with a first scenario that assumes a constant level of demand. The second scenario runs over six years on a regular basis, and expects a level of demand growth that would exceed the supply available. Data required to populate this model for both scenarios consist of:

- Current and projected levels of demand from elderly people for hospital care, broken down according to degree of complexity (i.e., frail and non-frail);

- The capacities of each sector (acute care, long term stay and short term stay);

- Proportions of elderly patients flowing down each pathway;

- Patients' average LOSs in each healthcare service along the pathways.

\subsubsection{Data Sources}

This study utilised several data sources. First, historical data of admissions and discharges of elderly patients were obtained from the Hospital In-Patient Enquiry (HIPE) database. HIPE is a computer-based information system designed to collect demographic, clinical and administrative data about discharges and deaths from Irish acute hospitals nationwide. All admissions and discharges of patients over 65 years of age were considered without exclusions. Second, data about bed capacities and average LOSs were collected from the HSE's annual healthcare national reports and surveys. The data collected have included valuable information about patients and their care journeys, such as arrival and admission times, sources of admission and discharge destinations.

As in other healthcare modelling projects, collecting the relevant data presented considerable 
challenges (Barjis 2011). The first was the dearth of data about certain parameters that were not captured by the HIPE. It is worth noting that the shortage of appropriate data caused a similar project studying care of the elderly in the UK to alter its objectives from producing quantitative results to only building a simulation model (Katsaliaki et al. 2005). The second challenge was that the data provided were in aggregate figures: for example, the numbers of patients discharged to multiple destinations was combined into a single figure, while modelling inputs require such data to be broken down into individual elements. The third problem with data in this case was inconsistencies between different data sources, such as variations in values between hospitals' data and annual reports. After numerous extended meetings with HSE officials, assumptions based on the opinions of experts in the field were used to overcome the absence of precise data and lack of information on how to decompose the aggregated figures.

\subsubsection{Data Analysis}

The sample collected included 153, 405 admissions to all acute public hospitals in Ireland which were gathered retrospectively for one year for patients discharged between January $1^{\text {st }} 2010$ and December $31^{\text {st }} 2010$. All diagnostic and procedure types were considered, and no exclusions were made, except for day-case patients. The analysis was performed using Microsoft Excel 2010. Data analysis and manipulation were applied to extract elderly acute care inpatient data from the raw data, after which data calibration was used to estimate model parameters, such as admission and discharge patterns, LOS, and to classify patients according to their needs.
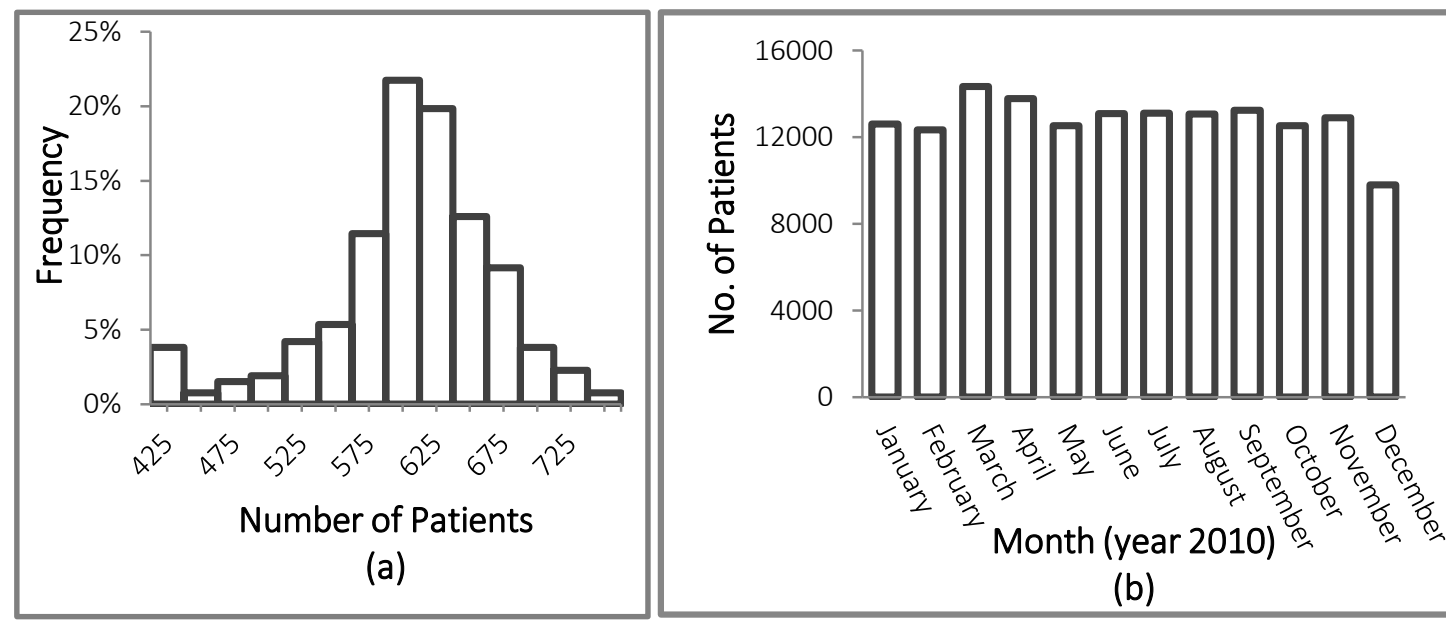

(b) 
Figure 8: Arrival Patterns of Elderly patients in 2010.

(Source: Data extracted from HIPE and analysed by authors)

Figure 8a shows the daily distribution of patient admissions. The total admissions of elderly patients were nearly 153,000 patients in 2010 . More than $75 \%$ of days have been witnessed admissions between 575 and 675 elderly patients, with an average of 587 patients and standard deviation of 88.26. The monthly admission numbers show a roughly uniform distribution (i.e., figure 8b), although the numbers for December were significantly lower than other months. Table 4 shows the destinations to which patients were discharged after their medication in acute care was completed.

Elderly patients differ according to the type and severity of their needs, so it is essential to understand their different arrival patterns to reflect the characteristics and needs of different groups of patients. Data were clustered to group elderly patients into frail and non-frail categories according to their LOSs in acute hospitals. This classification represents the degree of complexity (DOC) of their needs, based on the validated assumption that the most complex cases spend more time in hospitals. The majority of elderly patients (about 82\%) are classified as non-frail (with little or no complexity), and the remaining $18 \%$ as frail patients (with complex needs). Table 5 shows their different sources of admission categorized by age group. About $90 \%$ of all elderly patient demand originated from home. The table shows that the percentage of patients coming from home decreases as they get older, which reflects the fact that as they get older their dependency rises, and the possibility that they are coming from alternative care facilities also increases. $93 \%$ of patients in the 65-69 year age group come from their homes and $7 \%$ from elsewhere - but about $84 \%$ of patients in the $85+$ age group come from home and $16 \%$ from elsewhere, which emphasises the fact that older people - particularly frail patients - need more care and treatment than can be provided at home. Table 6 presents the number of beds provided for each type of service in the Irish health system, and Table 7 categorises patients' LOSs in each service. 
Table 4: Discharge Destinations Profile

\begin{tabular}{lccc}
\hline Discharge Destinations & \multicolumn{2}{c}{ Percentage of Patients } & \\
& Frail & Non-frail & All 65+ Patients \\
\hline Home & $24.2 \%$ & $78.4 \%$ & $6.1 \%$ \\
Another Hospital & $8.2 \%$ & $5.7 \%$ & $6.5 \%$ \\
Rehabilitation & $36.0 \%$ & $0.0 \%$ & $8.6 \%$ \\
Convalescence & $0.0 \%$ & $10.5 \%$ & $3.5 \%$ \\
Long Term Care & $19.5 \%$ & $0.0 \%$ & $6.1 \%$ \\
Died & $10.8 \%$ & $4.3 \%$ & $1.1 \%$ \\
Other & $1.3 \%$ & $1.1 \%$ & \\
Source: Data extracted from HIPE and analysed by authors & & \\
\hline
\end{tabular}

Table 5: Elderly Patients Admission Sources

\section{Sources of admission \%}

$\begin{array}{lllllll}\text { Age Group } & 65-69 & 70-74 & 75-79 & 80-84 & 85+ & \text { Total }\end{array}$

Source

\begin{tabular}{lrrrrrr}
\hline Home & $93 \%$ & $93 \%$ & $91 \%$ & $89 \%$ & $84 \%$ & $138156(90.1 \%)$ \\
Acute Hospital & $5 \%$ & $5 \%$ & $5 \%$ & $4 \%$ & $3 \%$ & $6743(4.4 \%)$ \\
\hline
\end{tabular}

Non-Acute/NH/Convalescence.

$\begin{array}{rrrrrr}1 \% & 2 \% & 4 \% & 7 \% & 12 \% & 7854(5.1 \%) \\ 1 \% & 1 \% & 0 \% & 0 \% & 0 \% & 653(0.4 \% \\ 100 \% & 100 \% & 100 \% & 100 \% & 100 \% & 153406(100 \%)\end{array}$

TOTAL

Source: Data extracted from HIPE and analysed by authors.

Table 6: Bed capacity levels

\begin{tabular}{lcc}
\hline Parameter & Value & Source \\
\hline Acute bed Capacity & 5000 patients & HSE (45\% of total Acute Bed Capacity) \\
LTC bed Capacity & 20748 patients & Long Stay Report (2011) \\
\hline
\end{tabular}




\begin{tabular}{lcc}
\hline Rehabilitation Bed Capacity. & 535 patients & Survey by HSE \\
Convalescence Bed Capacity & 1800 patients & Survey by HSE \\
\hline
\end{tabular}

Table 7: Average, min, max and standard deviation LOS.

\begin{tabular}{|c|c|c|c|c|}
\hline ALOS (\#days) & Mean & $\begin{array}{l}\text { Standard } \\
\text { Deviation }\end{array}$ & Min & Max \\
\hline Frail Discharge Plan (in ECW) & 28.5 & 0.5 & 27 & 30 \\
\hline Non-frail Discharge Plan (in non-ECW Acute bed) & 8 & 2 & 2 & 14 \\
\hline Rehab. & 50 & 3 & 41 & 59 \\
\hline Convalescence. & 48 & 1 & 45 & 51 \\
\hline Nursing Home-LTC & 1643 & 0 & 1643 & 1643 \\
\hline
\end{tabular}

\subsection{Model Validation}

To reduce the model's development cycle time and to increase confidence in its results, verification and validation procedures were carried out throughout the project's development phases. Several tests - mainly structure and behaviour tests - were applied to the model as suggested in the SD literature (Barlas 1996; Barlas 1989; Sterman 2000; Oliva 2003). First, the model was tested for dimensional consistency and conducted extreme condition tests to check its behaviour. For example, it was tested to ensure positive flows of patients and realistic behaviour of variables at the extremes (e.g., as if there is no demand or unconstrained capacity). The model's structure was discussed and verified with HSE officials and experts at different stages to ensure its consistency with the real-world problem. Other tests also were performed, such as for model boundary and integration errors. Since the model includes a random factor (i.e., patients' arrivals), the Euler integration method was adopted instead of the RungeKutta method, as suggested in the literature (Sterman 2000). The integration time step (dt) was set to half the shortest time parameter (i.e., 0.5 day). Further, delayed discharge data (HSE 2012b) are used to conduct a behaviour validation test, comparing the model output with the actual reported national figures. 
Table 8 provides a comparison of the actual and simulated data of the total number of older patients discharged from acute hospitals. The comparison reveals that the model underestimated the numbers of discharges to home, another acute care hospital, convalescence, death and other destinations, and overestimated those going to rehabilitation and long-term care destinations. Data deficiencies can explain these discrepancies, as input data may not capture some significant parameters completely. Figure 9 compares the simulated and actual number of older patients' delayed discharges in the base year 2010, and shows that the simulated data mirrors the actual data extremely well, with no-significant over- or under-estimations.

Table 8: Validation of simulation model

\begin{tabular}{|c|c|c|c|c|c|c|c|}
\hline \multicolumn{7}{|c|}{ Discharge Destination } & \\
\hline & & $\begin{array}{l}\text { Another } \\
\text { Hospital }\end{array}$ & $\begin{array}{r}\text { Rehabilitatio } \\
n\end{array}$ & Convalescence & $\begin{array}{r}\text { Long Term } \\
\text { Care }\end{array}$ & Death & Other \\
\hline Actual & 105237 & 9358 & 9971 & 13193 & 5369 & 9358 & 1687 \\
\hline Simulated & 90972 & 7122 & 10112 & 10375 & 5476 & 7561 & 1533 \\
\hline
\end{tabular}

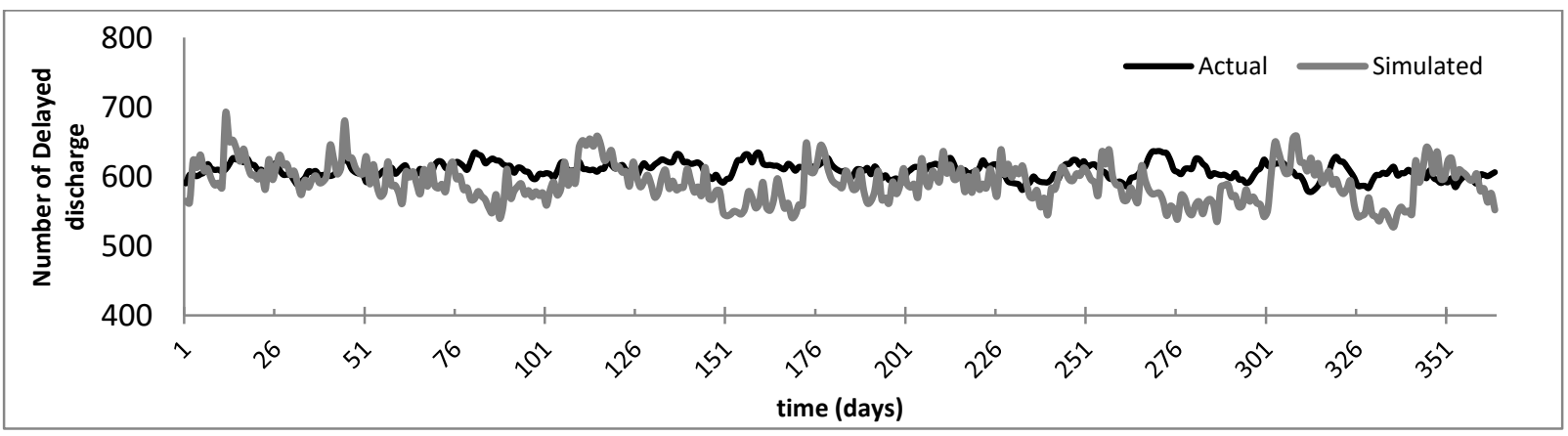

Figure 9: Model Validation using Number of delayed discharge

\section{POLICY ANALYSIS}

Ireland is experiencing significant population growth, especially in elderly people, who are expected to reach $15.4 \%$ of the population by 2021 (Wren et al. 2012). The demand for health care for elderly people is expected to increase dramatically in the coming years, and this growth will be 
associated with a rapid increase in the proportion of frail elderly patients, who are more likely to need long-term care. It is imperative that healthcare policymakers consider the projected future demand for care for elderly people when testing new policies. The worsening economic outlook has led to substantial cuts in public healthcare expenditure, which resulted in an estimated 1,274 acute care beds being closed between 2007 and 2011 (Institute 2011), suggesting that increasing acute care bed capacities was not a feasible intervention policy. Table 9 summarises the policies that the HSE's officials suggested as possible interventions to relieve the pressure on acute care due to delayed discharge problems. They recommended policies 1-3, and our research group suggested combining multiple policies together (i.e., in policies 4 and 5).

These policies were explored and evaluated under two scenarios. The first examined the impact of the proposed solutions in short term planning under static demand conditions, while the second scenario was designed to evaluate those policies over a longer-term planning horizon, assuming continuous demand increases. Connell and Pringle's (2002) projection is used to extrapolate future elderly population numbers: a cubic polynomial curve fitting was applied to estimate a closed form demand generation function as shown in equation 26.

$$
\text { Proj_Eld_pop }(\tau)=\beta_{3} \tau^{3}+\beta_{3} \tau^{2}+\beta_{1} \tau+\beta_{0}
$$

Proj_Eld_pop $(\tau)$ is the projected elderly population at time $\tau$, which is scaled and centred at the mean using equation 27:

$$
\tau=\frac{\left(t^{*}+\frac{t}{365}\right)-\mu}{\sigma}
$$

where $t^{*}$ is the reference year of the study (here, 2010), and $\mu$ is the mean time of the projected data. Time $t$ represents the current simulation time, and $\sigma$ is the standard deviation of time.

\section{Table 9:}

\section{Policy interventions descriptions.}

$\begin{array}{lll}\text { Policy } & \text { Policy Type } & \text { Policy Description }\end{array}$




\begin{tabular}{|c|c|c|}
\hline Name & & \\
\hline BAU & & $\begin{array}{l}\text { Business as usual (BAU) was used for the base model run, with the aim of exploring } \\
\text { how the model behaved with the current capacities. }\end{array}$ \\
\hline Policy 1 & $\begin{array}{l}\text { Stock } \\
\text { intervention }\end{array}$ & $\begin{array}{l}\text { Based on current patterns of community provision, Wren et al. (2012) have suggested } \\
\text { that around } 20 \% \text { more nursing home places will be needed over the next five years. } \\
\text { This policy is therefore designed to investigate the effects of a } 20 \% \text { expansion in post- } \\
\text { acute bed capacity }\end{array}$ \\
\hline Policy 2 & $\begin{array}{l}\text { Flow } \\
\text { intervention }\end{array}$ & $\begin{array}{l}\text { This pre-acute policy intervention is designed to increase GPs' access to community } \\
\text { services to avoid unnecessary admissions to acute systems. This reduction in the need } \\
\text { for hospitalization is expected to mitigate the pressure on acute hospital resources. It } \\
\text { is implemented in the model by a } 15 \% \text { decrease in elderly arrivals at acute EDs }\end{array}$ \\
\hline Policy 3 & $\begin{array}{l}\text { Flow } \\
\text { intervention }\end{array}$ & $\begin{array}{l}\text { This post-acute flow policy intervention is focused on long-term care facilities, in } \\
\text { particular nursing homes, where patients stay for extended periods. It aims to examine } \\
\text { the impact of increasing discharge rates from long-term care facilities. Improvements } \\
\text { in homecare packages and home help scheme provision can reduce LTC admissions } \\
\text { or increase LTC discharge rates, as well as reducing patients' average LOS in LTC } \\
\text { facilities. The policy is implemented in the model by a } 10 \% \text { increase in numbers of } \\
\text { patients discharged from LTC facilities. }\end{array}$ \\
\hline Policy 4 & $\begin{array}{l}\text { Stock \& Flow } \\
\text { interventions }\end{array}$ & A combination of policies $1 \& 2$. \\
\hline Policy 5 & $\begin{array}{l}\text { Stock \& Flow } \\
\text { interventions }\end{array}$ & A combination of policies $1,2, \& 3$. \\
\hline
\end{tabular}

\subsection{Scenario 1: Stationary Demand}

The first scenario assumes stationary demand using the base year 2010. The model runs for three years representing 1095 days (i.e., 365*3) between January 1st, 2010 and December 31st, 2013. As the aim of this scenario is to test and explore how the health system behaves in the medium-term with current demand levels, so the assumption of constant demand is seen as realistic. The model was initialised with patient numbers in acute care with acute bed and post-acute care capacities set at $80 \%$, and with empty waiting lists for the various healthcare services. The first year is considered a warm-up period designed to eliminate any bias in the initial conditions: the policy interventions are all introduced 
after this first year. For ease of viewing, the system's behaviour for each policy is presented separately.

Figure 10 shows the simulation results of the first scenario of the different policies against the business as usual (BAU) model. Assuming constant need, the BAU model shows that, with no policy interventions, the delayed discharge will reach equilibrium at an average of 600 patients a day (Figure 10). The influence of expanding post-acute capacity (i.e. policy 1) on delayed discharge appeared to be quite useful in the short-term, with numbers of delayed discharge declining initially to a constant level, but then returning to their original levels. This behaviour illustrates the time-limited effect of capacity expansion even when demand is constant: as soon as the additional capacity is fully utilized, the waiting lists for post-acute services grow again. The impacts of different policies are not immediate and can take some time to appear, which explains the steady decline in delayed discharge numbers after they are applied (i.e., at the dotted grey line).

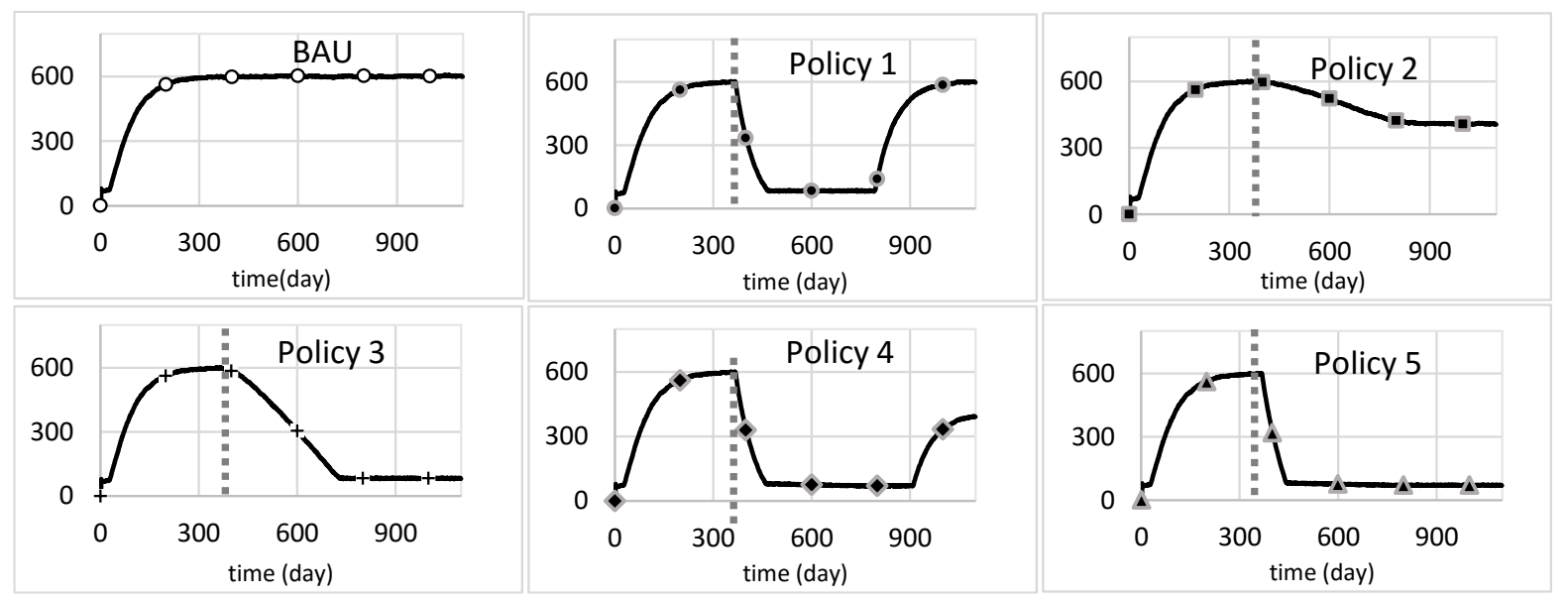

Figure 10: number of delayed discharge (y-axis) under different policy interventions assuming stationary demand. (Dotted grey line indicates start time of policy interventions.)

Under the BAU, ALOS in acute hospitals declined from 64 days to 20 days, and the percentage of blocked beds fell from $11.5 \%$ to less than $2 \%$ after introducing policy 3 (fig. 11). This figure shows clearly that there is a decrease in elderly patients' average lengths of stay (ALOS) in acute care and in percentages of blocked acute beds under any of the policies. Mitigating the acute care demand via a $15 \%$ reduction in emergency demand from elderly patients (policy 2) was sufficient to reduce the blocked beds percentage from nearly $12 \%$ to $8 \%$. In contrast, policy 3 seems to achieve the most 
significant drop in delayed discharge numbers, but using policy 5 seemed to deliver no significant improvement over policy 3. Even under policy 4, delayed discharges continue to increase, although after a rather longer period than under policy 2. Adopting policies 4 or 5 realised insignificant improvements compared to policy 3. Under the current system capacity, Figure 12 demonstrates that the percentage of patients who did not receive alternative care after waiting more than two months after completing their acute treatment grows continuously and reaches $12 \%$. It is clear that access to post-acute care could be greatly improved by applying policies 3,4 or 5 , although the impact of policies 4 or 5 only offer minimal improvement over policy 3 , indicating that improving the outflow from 'stepdown' facilities has greater potential influence than reducing acute-care demand or even increasing acute bed capacity.

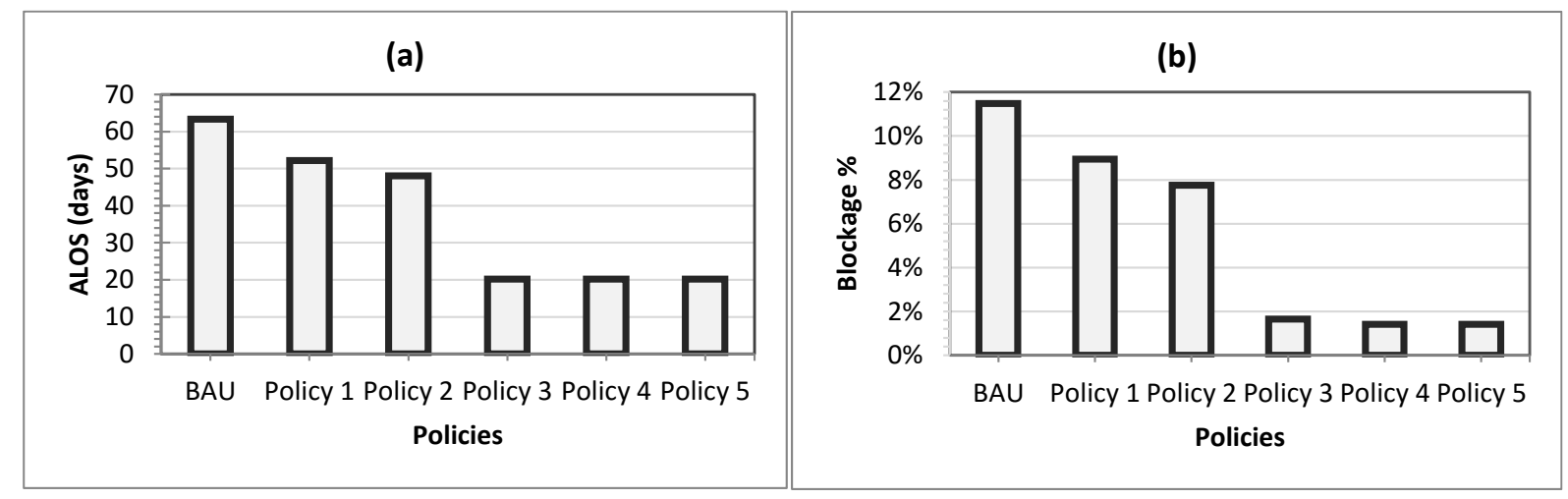

Figure 11: Average LOS of Elderly Frail Patients in acute care (a) and bed blockage percent (b)

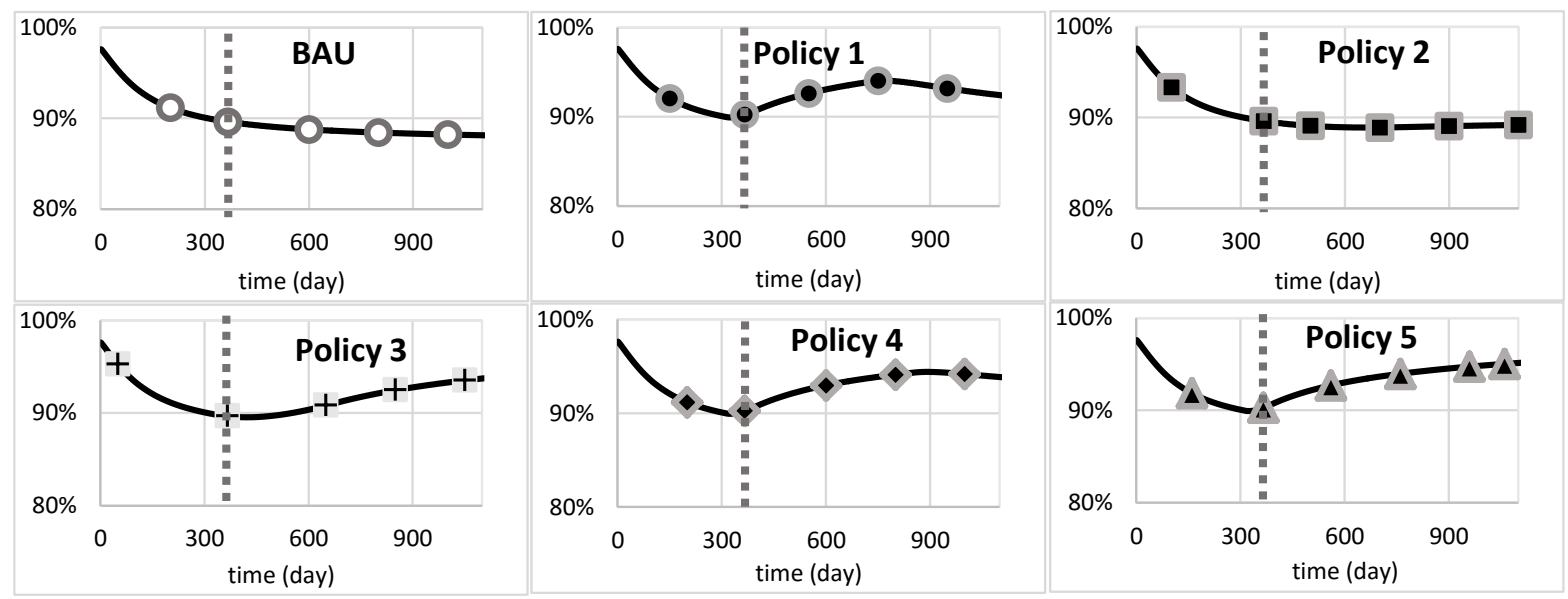

Figure 12: Post-acute bed accessibility (y-axis) (Scenario 1)

\section{Scenario 2: Permanently changing Demand}


In the second scenario, the continuous changes in patients' demand and demographics are included in the model. The aim of this scenario is to explore the behaviour of the system and the proposed policies over the long-term under the assumption of growing demand. The model runs for six years, representing 2190 days (i.e., 365*6) between January 1st, 2010 and December 31st, 2016. This scenario follows the same assumptions used in Scenario one, but demand is modelled using equations 26 and 27.

The BAU model (Figure 13) shows that, with no policy interventions, the delayed discharge figures will continue to grow. Clearly, (as noted above) there is a cost associated with patients waiting in acute care beds, which also manifests itself in the length of time patients have to wait for 'step-down' care services. The effect of increasing LTC bed capacity (i.e., Policy 1; Figure 13) on delayed discharge is only minimal and temporary: delayed discharge numbers decrease initially, but only for a short period, then return to their increasing trend. Increasing GPs access to community services (Policy 2; Figure 13) again brings some short-term improvement by reducing pressure on the acute care system, but increasing demand again counteracts the impact of this policy over time. Similarly, Policy 3 works to increase the throughput of LTC facilities, and the improvement lasts for longer. but the demand for LTC services increases over time more rapidly than discharges from acute care. Policy 4 again fails to mitigate the delayed discharge problem, despite being a mixture of policies 1 and 2 - in fact, none of the first four policies can cope with the increasing long-term service demand, and their impacts are minimal compared to that of demand growth. However, policy 5 appears to be more effective than the others in reducing delayed discharge numbers.

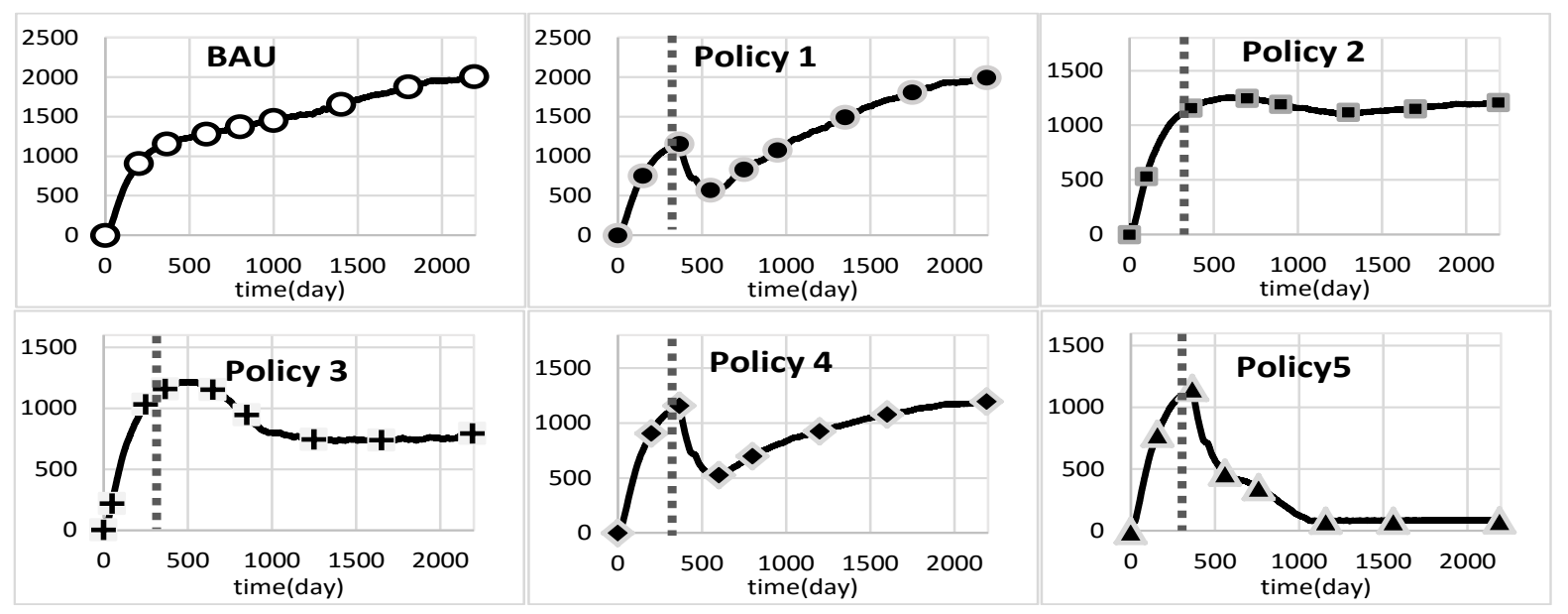

Figure 13: Numbers of delayed discharges (y-axis) under different policy interventions assuming stationary 
demand (Scenario 2).

Figure 14 shows that the ALOS of elderly frail patients in acute care increases in line with delayed discharge numbers under all the policies. Although the first four policies all succeed in decreasing ALOS initially, they fail to maintain the decline in the rates - after a while, the figures start to grow again, more or less rapidly. In fact Policy 3 shows a much slower rate of re-growth - even after 6 years, LOS is still barely a third of what it was at its peak. Overall, policy 5 was the most effective in decreasing elderly frail patients' ALOS in acute hospitals as the inclusion of policy 3 into policy 5 that makes it the best option.

Figure 15 shows the outcomes for post-acute bed accessibility under the various policies. Policies 1 and 4 improve post-acute accessibility for a while, but as soon as demand increases, their behaviour declines again to $76 \%$ and $85 \%$ for the two policies respectively. Post-acute accessibility also continues to show steady dynamics under both policies 3 and 4 . The average acute occupancy level is about $82 \%$ for policy 5 - the lowest level achieved by any of the policies - and access to post-acute care reaches over $93 \%$.

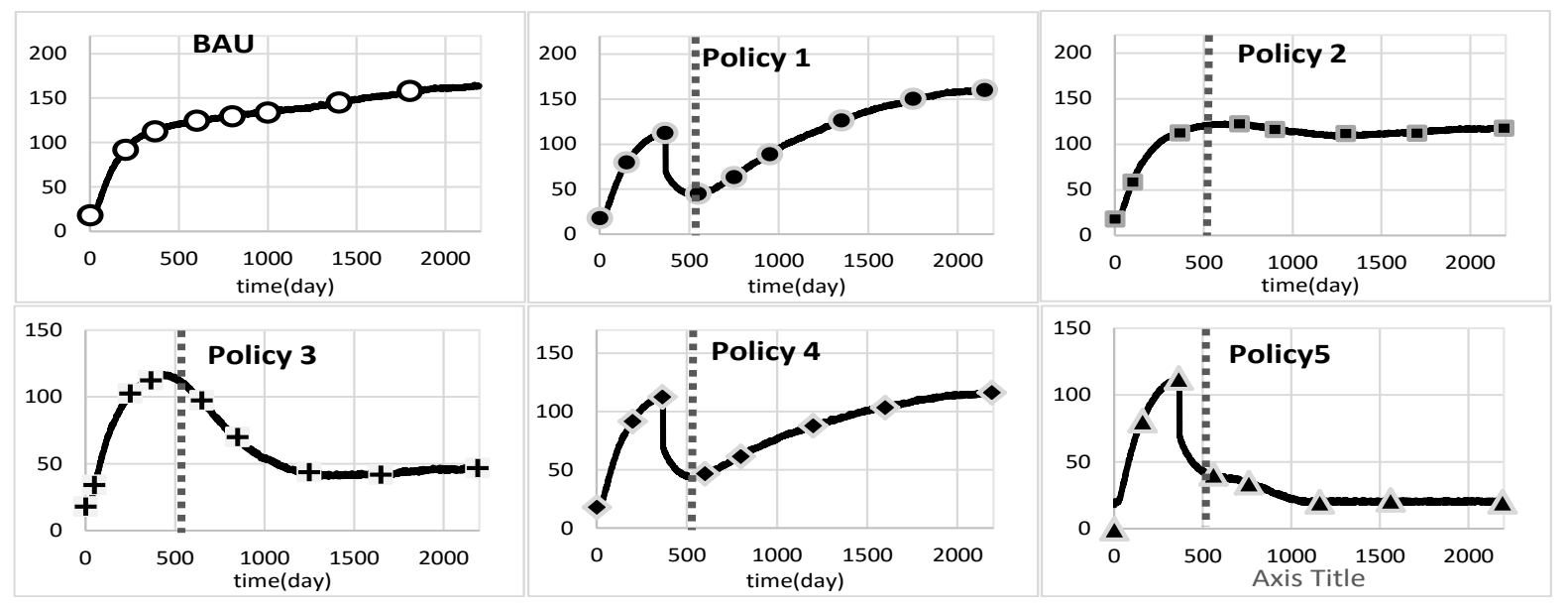

Figure 14: ALOS of Frail Elderly Patients in acute care (y-axis) (Scenario 2) 


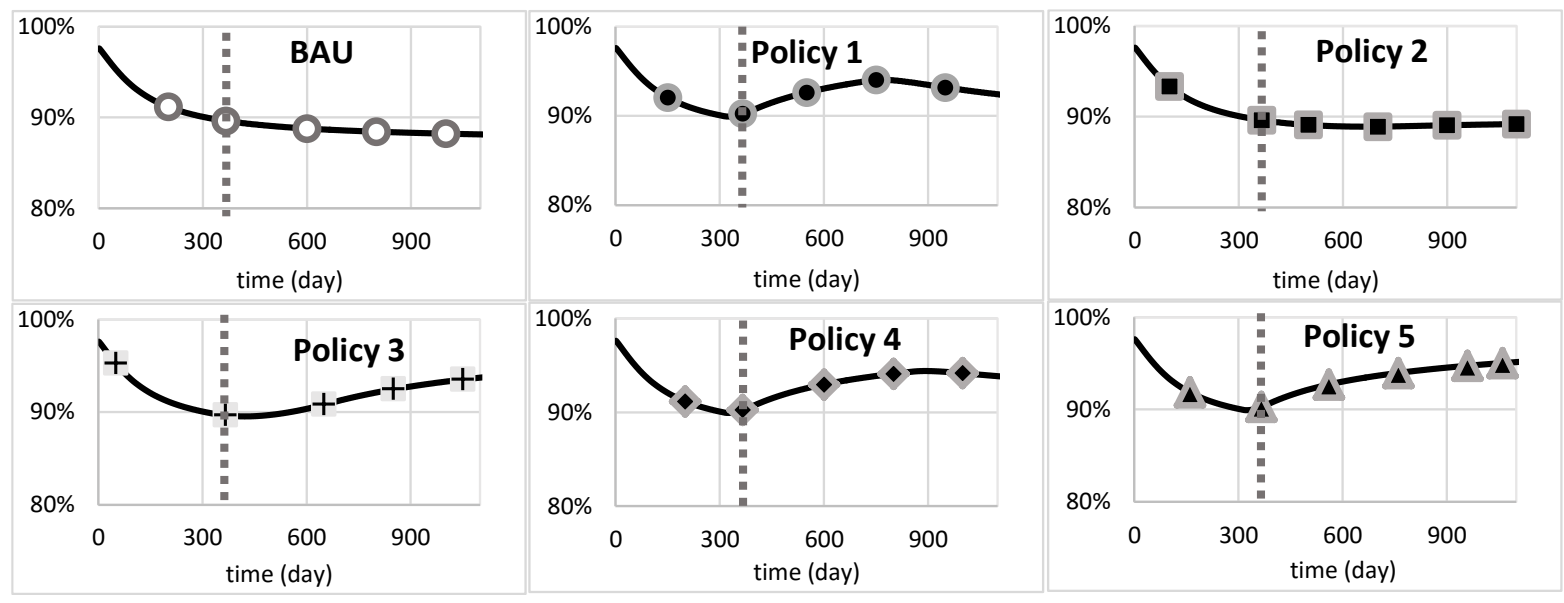

Figure 15: Post-acute Accessibility (y-axis) (Scenario 2).

\section{DISCUSSION}

Results from the base model simulation revealed that there are, on average, about 600 delayed discharges daily, and more than $75 \%$ of these are due to delays in making long-term care arrangements. Given the costs of running an acute bed are $€ 850$ per night, the cost of caring for 600 delayed patients exceeds $€ 0.5 \mathrm{~m}$ per day. Hence, decreasing the number of delayed discharges could lead to significant financial savings that could be re-directed into improving community-based care services.

Healthcare management suggests policies based on increasing post-acute capacity to react to the growing demand from elderly people. The intended consequences of this intervention are to reduce the number of inpatients waiting for post-acute services and to cater for unmet demand more effectively by facilitating more and quicker discharges to 'step-down' facilities. However, this policy has the inevitable consequence of increasing demand for post-hospital care. Thus, after a while, post-acute service capacity is full again, so the effectiveness of the post-acute expansion is limited: a situation that is illustrated in Figure 16.

The outcomes of running capacity expansion policy in the model reveal that increasing post-acute bed capacity barely provides a temporary solution and its impact is insignificant over longer periods. When post-acute bed capacity is increased, more patients will be admitted to post-acute services, resulting in increasing the availability of acute beds. But the effect of that capacity expansion can only offer a temporary solution - as soon as the additional capacity is used up, the situation gradually 
deteriorates again. The number of patients waiting for the services accumulates steadily, waiting times escalate again and the proportion of acute beds that are blocked increases once more. Capacity expansion policy is an example of stock intervention policies that have time-limited effects, and may even stimulate more demand.

On the other hand, the model simulations show that flow intervention policies can be very effective in reducing the pressure on acute care beds if they are combined with expansions in post-acute care capacities. The combination of the three policies suggested by healthcare managers in this case is shown to be more likely to be effective in improving health care system performance than implementing any of them separately. Creating new channels to reduce emergency admissions and lengths of stay in longterm care can make significant improvement if the demand is steady.

Testing policies shows the unintended consequences of behavioural effects and provides insights into the types of policies that could be used to improve healthcare system performance. Also, recognising the leverage effects of policies, and the learning involved in gaining deeper understanding of problems can help reduce implementation times and costs.

The simulation model provides quantitative insights into the numbers of delayed discharges that could result from implementing different policy interventions over time at different points along patient pathways. Implementing mixed policies reduces the average lengths of stay in acute care and frees up beds for new admissions, and could create opportunities to further reduce acute bed capacity. Policy 5 - a combination of all the policies healthcare executives suggested - achieved the lowest acute bed occupancy and delayed discharge rates. Reducing delayed discharges offers the HSE executive the opportunity to save on the significant costs involved. Increasing LTC capacity could perhaps be achieved via greater private sector investments, perhaps encouraged by state mechanisms such as tax incentives. 


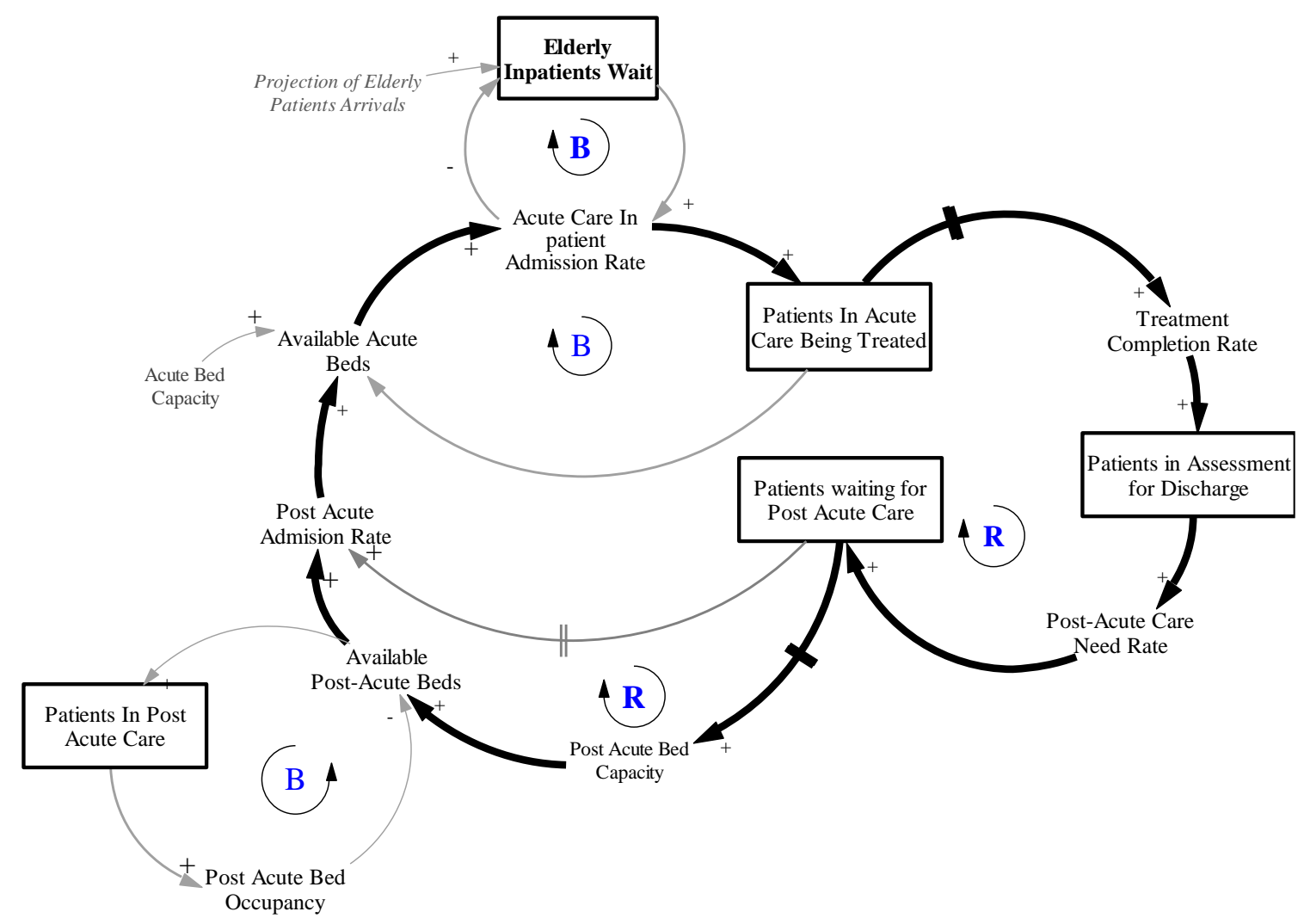

Figure 16: Unintended consequences associated with capacity expansion of post-hospital services.

\section{CONCLUSION}

The mounting demand for elderly healthcare services due to population aging is confronting Irish healthcare executives with critical capacity planning issues. Addressing these challenges requires advanced planning tools that can handle the complex interlinked service constraints on proposed interventions and operational strategies. This study has used conceptual modelling to illustrate different elderly patients' care pathways, and this qualitative model provided a better understanding of the resources required during their care journeys. A system dynamics model was developed to help the decision-making team to understand the dynamic complexity caused by the system's different elements. Causal loop diagram was used to identify the links between the key variables and to illustrate the problem's feedback structure. This phase was followed by developing a stock and flow diagram to track patients' flows from one point to another through the system.

Although the model is limited in size and complexity, it can be of great benefit to policy makers in attempting to understand and solve the problems of the delayed discharge of elderly patients and in 
anticipating the outcomes of potential relevant interventions. The simulation model provides valuable insights in predicting the impact of future changes on service performance. Its primary advantage is its ability to test different hypothetical scenarios quantitatively, given the ease with which the capacities of acute and post-acute care or even the model's parameters can be changed. Implementing a combination of stock and flow policies seems to be more efficient than using either separately. The impact of stock interventions such as increasing post-acute capacity will only relieve the problem temporarily, and may even stimulate greater demand, although this may seem counter-intuitive. But a mixed strategy of stock and flow interventions was shown to be potentially very effective in reducing pressures on acute care provision. These findings were very useful in providing insightful learning for planners. This outcome also explains the importance of using advanced planning tools such as SD, and shows how they can evaluate proposed policies before their implementation.

Deciding on clear policies for the health service at the national level promises to support the next phase of the project, which concerns the role of local Irish communities in the long-term planning for non-acute services for elderly people. In this process, the model outcomes will be subject to the demographic characteristics of local communities' catchment areas in terms of the availability of both community services and acute hospitals. Ongoing data collection will be required in each local community to enable the model to help decision makers identify the required local level interventions.

There are four aspects of this study that can be considered as limitations, and also as suggested opportunities for future research channels. Its first limitation is its reliance on a single type of resource (i.e., bed capacity) as the primary determinant of delayed discharge to the neglect of other possible resources (such as social workers' availability). A second potential limitation is the postulation that current patterns of care needs and the health status of elderly patients will remain identical to those of the base year over time. Although the assumption that elderly patients will have identical health status in the future to those they exhibit in the base year is valid to some extent, this hypothesis could be examined as a different scenario in the model used here. Third, the model focused on emergency patients - further work could attempt to extend its scope to incorporate elective patients, using such inand out-flows as elective admissions and cancellations. A final limitation relates to the difficulties of data collection. Although HSE has a huge database including historical data and statistics, this study 
identified that data gaps exist such as capacities and LOS of different services, although the reasons for

the lack of some information and the inconsistencies of reports generated from the database are unclear.

\section{References}

Abo-Hamad, W. \& Arisha, A., 2014. Multi-criteria approach using simulation-based balanced scorecard for supporting decisions in health-care facilities: an emergency department case study. Health Systems, 3(4359). Available at: http://www.palgrave-journals.com/hs/journal/vaop/ncurrent/abs/hs201311a.html [Accessed January 17, 2014].

Abo-Hamad, W. \& Arisha, A., 2013. Simulation-based framework to improve patient experience in an emergency department. European Journal of Operational Research, 224(1), pp.154-166.

Barjis, J., 2011. Healthcare simulation and its potential areas and future trends. SCS M\&S Magazine, 2(5). Available at: http://www.iness.org.br/conteudo/pub/003/cont/000081/000081.pdf [Accessed October 16, 2014].

Barlas, Y., 1996. Formal aspects of model validity and validation in system dynamics. System Dynamics Review, 12(3), pp.183-210. Available at: http://doi.wiley.com/10.1002/\%28SICI\%291099$1727 \% 28199623 \% 2912 \% 3 \mathrm{~A} 3 \% 3 \mathrm{C} 183 \% 3 \mathrm{~A} \% 3 \mathrm{AAID}-\mathrm{SDR} 103 \% 3 \mathrm{E} 3.0 . \mathrm{CO} \% 3 \mathrm{~B} 2-4$.

Barlas, Y., 1989. Multiple tests for validation of system dynamics type of simulation models. European Journal of Operational Research, 42(1), pp.59-87. Available at: http://www.sciencedirect.com/science/article/pii/0377221789900593 [Accessed April 14, 2014].

Barrett, A. et al., 2011. Fifty Plus in Ireland 2011, First results from the Irish Longitudinal Study on Ageing (TILDA), Dublin.

Brailsford, S. \& Hilton, N., 2001. A comparison of discrete event simulation and system dynamics for modelling health care systems. In Proceedings from ORAHS 2000, pp.18-39. Available at: http://eprints.soton.ac.uk/35689/1/glasgow_paper.pdf [Accessed September 2, 2013].

Bryan, K., 2010. Policies for reducing delayed discharge from hospital. British medical bulletin, 95, pp.33-46. Available at: http://www.ncbi.nlm.nih.gov/pubmed/20647227 [Accessed February 14, 2013].

Bryan, K., Gage, H. \& Gilbert, K., 2006. Delayed transfers of older people from hospital: Causes and policy implications. Health Policy, 76(2), pp.194-201. Available at: http://www.sciencedirect.com/science/article/pii/S0168851005001363 [Accessed January 17, 2014].

Burke, E.K. et al., 2008. A hybrid heuristic ordering and variable neighbourhood search for the nurse rostering problem. European Journal of Operational Research, 188(2), pp.330-341. Available at: http://linkinghub.elsevier.com/retrieve/pii/S0377221707004390 [Accessed October 21, 2013].

Cai, M.C., Yang, X.G. \& Zhang, J.Z., 1999. The Complexity Analysis of the Inverse Center Location Problem. Journal of Global Optimization, 15(2), pp.213-218. Available at: http://link.springer.com/article/10.1023/A\%3A1008360312607 [Accessed January 17, 2014].

Chalfin, D.B. et al., 2007. Impact of delayed transfer of critically ill patients from the emergency department to the intensive care unit. Critical care medicine, 35(6), pp.1477-83. Available at: http://www.ncbi.nlm.nih.gov/pubmed/17440421 [Accessed February 16, 2015].

Connell, P. \& Pringle, D., 2004. POPULATION AGEING IN IRELAND: Projections 2002-2021, Dublin.

Cooke, D. et al., 2007. Introducing System Dynamics Modeling to Health Care in Alberta. In Proceedings of the 2007 System Dynamics Conference. The System Dynamics Society.

Costa, A.P. et al., 2012. Acute care inpatients with long-term delayed-discharge: evidence from a Canadian health region. $B M C$ health services research, 12, p.172. Available at: http://www.pubmedcentral.nih.gov/articlerender.fcgi?artid=3424132\&tool=pmcentrez\&rendertype=abstra ct.

Covinsky, K.E. et al., 2003. Loss of independence in activities of daily living in older adults hospitalized with medical illnesses: increased vulnerability with age. Journal of the American Geriatrics Society, 51(4), pp.451-8. Available at: http://www.ncbi.nlm.nih.gov/pubmed/12657063 [Accessed January 17, 2014].

Crimmins, E.M., 2004. Trends in the health of the elderly. Annual review of public health, 25, pp.79-98. Available at: http://www.ncbi.nlm.nih.gov/pubmed/15015913.

Davies, R. \& Davies, H., 1994. Modelling patient flows and resource provision in health systems. Omega, 22(2), pp.123-131. Available at: http://www.sciencedirect.com/science/article/pii/0305048394900736 [Accessed January 17, 2014].

Department of Health, 2010. Long-Stay Activity Statistics, Available at: http://www.dohc.ie/publications/pdf/long_stay_2010.pdf. 
Desai, M.S. et al., 2008. Modelling of Hampshire Adult Services-gearing up for future demands. Health Care Management Science, 11(2), pp.167-176. Available at: http://link.springer.com/10.1007/s10729-007-90490 [Accessed January 17, 2014].

Duguay, C. \& Chetouane, F., 2007. Modeling and improving emergency department systems using discrete event simulation. Simulation, 83(4). Available at: http://sim.sagepub.com/content/83/4/311.short [Accessed January 17, 2014].

Eldabi, T., Paul, R.J. \& Young, T., 2006. Simulation modelling in healthcare: reviewing legacies and investigating futures. Journal of the Operational Research Society, 58(2), pp.262-270. Available at: http://www.palgrave-journals.com/jors/journal/v58/n2/abs/2602222a.html [Accessed January 17, 2014].

Evetovits, T., European Observatory on Health Systems policies \& WHO Regional Office Europe, 2012. Health system responses to financial pressures in Ireland: policy options in an international context, Dublin: Department of Health (DoH). Available at: http://www.lenus.ie/hse/handle/10147/263215 [Accessed November 11, 2014].

Gallagher, P., Henry, C. \& O'Callaghan, N., 2008. Do relatives of elderly patients block the discharge process? Irish medical journal, 101(3), pp.70-2. Available at: http://www.ncbi.nlm.nih.gov/pubmed/18540541 [Accessed March 5, 2015].

Glasby, J., 2004. Show Me the Way to go Home: A Narrative Review of the Literature on Delayed Hospital Discharges and Older People. British Journal of Social Work, 34(8), pp.1189-1197. Available at: http://bjsw.oxfordjournals.org/content/34/8/1189.abstract [Accessed November 11, 2014].

Goldman, D.P. et al., 2005. Consequences of health trends and medical innovation for the future elderly. Health affairs (Project Hope), 24 Suppl 2, pp.W5R5-17. Available at: http://www.ncbi.nlm.nih.gov/pubmed/16186147 [Accessed October 22, 2014].

Heidenberger, K. \& Flessa, S., 1993. A system dynamics model for AIDS policy support in Tanzania. European Journal of Operational Research, 70(2), pp.167-176. Available at: http://www.sciencedirect.com/science/article/pii/037722179390036M [Accessed May 11, 2015].

HRID \& ESRI, 2013. Acitivity in Acute Public Hospitals in Ireland 2012,

HSE, 2012a. Delayed Discharge National Report Dublin:, Dublin. Available at: http://www.oireachtas.ie/parliament/media/committees/pac/correspondence/2012-meeting512009/[PACR-593]Correspondence-3A.7.pdf.

HSE, 2012b. Health Service Executive Annual Report and Financial Statements,

HSE, 2014. National Service Available 2014, at: http://www.hse.ie/eng/services/Publications/corporate/serviceplan2014/nationalserviceplan2014.pdf.

Institute, T.E. and S.R., 2011. Long-Stay Activity Statistics 2011, Available at: http://www.esri.ie/_uuid/462574ea-80a8-4bb4-96ea-31bf0fdcfc2d/2011-HIPE-Annual-Report-Final.pdf.

Kampmann, C. \& Sterman, J., 1998. Feedback complexity, bounded rationality, and market dynamics. Memo D4802, System Dynamics Group. A. Available http://citeseerx.ist.psu.edu/viewdoc/download?doi=10.1.1.202.7692\&rep=rep1\&type=pdf [Accessed January 17, 2014].

Katsaliaki, K. et al., 2005. Mapping care pathways for the elderly. Journal of Health Organisation and Management, $19(1)$ pp.57-72.

Available

at: http://www.emeraldinsight.com/10.1108/14777260510592130 [Accessed September 2, 2013].

Kydd, A., 2008. The patient experience of being a delayed discharge. Journal of nursing management, 16(2), pp.121-127. Available at: http://onlinelibrary.wiley.com/doi/10.1111/j.1365-2834.2008.00848.x/full [Accessed January 17, 2014].

Lakdawalla, D.N., Bhattacharya, J. \& Goldman, D.P., 2004. Are The Young Becoming More Disabled? Health Affairs, 23(1), pp.168-176. Available at: http://content.healthaffairs.org/cgi/doi/10.1377/hlthaff.23.1.168 [Accessed October 22, 2014].

Lane, D. \& Husemann, E., 2007. System dynamics mapping of acute patient flows. Journal of the Operational RESEARCH SOCIETY.

Liotta, G. \& Mancinelli, S., 2012. Determinants of acute hospital care use by elderly patients in Italy from 1996 to 2006. Archives of Gerontology and Geriatrics, 54(3), pp.e364-e369. Available at: http://www.sciencedirect.com/science/article/pii/S0167494311002275 [Accessed January 17, 2014].

Litvak, N. et al., 2008. Managing the overflow of intensive care patients. European Journal of Operational Research, 158(3), pp.998-1010. Available at: http://doc.utwente.nl/63646/1/2008XLitvakRijsbergenBoucherieHoudenhoven.pdf [Accessed January 17, 2014].

Majeed, M.U. et al., 2012. Delay in discharge and its impact on unnecessary hospital bed occupancy. BMC health services research, 12(1), p.410. Available at: http://www.pubmedcentral.nih.gov/articlerender.fcgi?artid=3511236\&tool=pmcentrez\&rendertype=abstra ct [Accessed February 14, 2013]. 
Masnick, K. \& McDonnell, G., 2010. A model linking clinical workforce skill mix planning to health and health care dynamics. Human resources for health, 8, p.11.

McDermid, R.C. \& Bagshaw, S.M., 2011. ICU and critical care outreach for the elderly. Best practice \& research. Clinical anaesthesiology, 25(3), pp.439-49. Available at: http://www.ncbi.nlm.nih.gov/pubmed/21925408 [Accessed January 17, 2014].

Monefeldt, C., Lane, D. \& Rosenhead, J., 2000. Looking in the wrong place for healthcare improvements: A system dynamics study of an accident and emergency department. Journal of the operational reserach Society, 51(5), pp.518-531. Available at: http://www.jstor.org/stable/10.2307/254183 [Accessed January $17,2014]$.

Morecroft, J.D.W., 1988. System dynamics and microworlds for policymakers. European Journal of Operational Research, 35(3), pp.301-320. Available at: http://www.sciencedirect.com/science/article/pii/0377221788902214 [Accessed May 11, 2015].

Ng, A., Sy, C. \& Li, J., 2011. A system dynamics model of Singapore healthcare affordability. In Proceedings of the Winter Simulation Conference (WSC). Phoenix, AZ, p. 10.1109/WSC.2011.6147853. Available at: http://ieeexplore.ieee.org/xpls/abs_all.jsp?arnumber=6147853 [Accessed September 2, 2013].

Oliva, R., 2003. Model calibration as a testing strategy for system dynamics models. European Journal of Operational Research, 151, pp.552-568.

Papadimitriou, C.H. \& Steiglitz, K., 1998. Combinatorial Optimization: Algorithms and Complexity (Dover Books on Computer Science), Dover Publications. Available at: http://www.amazon.com/CombinatorialOptimization-Algorithms-Complexity-Computer/dp/0486402584 [Accessed January 17, 2014].

Paul, J.A. \& Hariharan, G., 2007. Hospital capacity planning for efficient disaster mitigation during a bioterrorist attack. Proceedings - Winter Simulation Conference, (1976), pp.1139-1147.

Piersa, R.D. et al., 2013. Advance Care Planning in terminally ill and frail older persons. Patient Education and Counseling, 90(3), pp.323-329. Available at: http://www.sciencedirect.com/science/article/pii/S0738399111003752 [Accessed January 17, 2014].

Ragab, Mo. et al., 2013. Using Modelling and Simulation to Improve Elderly Care in Ireland: A Case Study. International Journal on Advances in Life Sciences, 5(1), pp.89-102. Available at: http://arrow.dit.ie/buschmarart/122/ [Accessed August 7, 2013].

Robertson, A., Bloom, J. \& Duckett, S., 2012. Development of an interactive model for planning the care workforce for Alberta: case study. Human Resources for Health, 10(1), p.22.

Senge, P.M., 2006. The Fifth Discipline: The Art \& Practice of The Learning Organization, Doubleday. Available at: http://www.amazon.com/The-Fifth-Discipline-Practice-Organization/dp/0385517254 [Accessed January 17, 2014].

Sterman, J.D., 2000. Business Dynamics: Systems Thinking and Modeling for a Complex World, McGrawHill/Irwin. Available at: http://www.amazon.com/Business-Dynamics-Systems-ThinkingModeling/dp/007238915X [Accessed January 17, 2014].

Sweetser, A., 1999. A comparison of system dynamics (SD) and discrete event simulation (DES). In System Dynamic Society. Available at: http://www.systemdynamics.org/conferences/1999/PAPERS/PARA78.PDF [Accessed November 10, 2014].

Thorwarth, M., Arisha, A. \& Harper, P., 2009. Simulation model to investigate flexible workload management for healthcare and servicescape environment. Proceedings of the 2009 Winter Simulation Conference (WSC), pp.1946-1956.

Available

at: http://ieeexplore.ieee.org/lpdocs/epic03/wrapper.htm?arnumber=5429210.

Vetter, N., 2003. Inappropriately delayed discharge from hospital: what do we know? BMJ (Clinical research ed.), 326(7395), pp.927-8. Available at: http://www.pubmedcentral.nih.gov/articlerender.fcgi?artid=1125831\&tool=pmcentrez\&rendertype=abstra ct.

Walker, B. \& Haslett, T., 2001. System dynamics and action research in aged care. Australian Health Review, 24(1), p.183. Available at: http://www.publish.csiro.au/view/journals/dsp_journal_fulltext.cfm?nid=270\&f=AH010183 [Accessed January 17, 2014].

WHO, 2011. 10 facts on ageing and the life course. Available at: http://www.who.int/features/factfiles/ageing/en/index.html.

Wolstenholme, E., 1999. A patient flow perspective of UK Health Services: exploring the case for new "intermediate care" initiatives. System Dynamics Review, 15(3), pp.253-271. Available at: http://onlinelibrary.wiley.com/doi/10.1002/(SICI)1099-1727(199923)15:3\%3C253::AID-

SDR172\%3E3.0.CO;2-P/abstract [Accessed January 17, 2014].

Wren, M. et al., 2012. Towards the Development of a Predictive Model of Long-Term Care Demand For Northern Ireland and the Republic of Ireland, Available at: https://medicine.tcd.ie/health_policy_management/assets/pdf/CARDI report.pdf. 
